\title{
A Mesoscopic Simulation Model for Airport Curbside Management
}

\author{
Tyler M. Harris, Mehdi Nourinejad, and Matthew J. Roorda \\ Department of Civil Engineering, University of Toronto, 35 St. George Street, Toronto, ON, Canada M5S 1A4 \\ Correspondence should be addressed to Mehdi Nourinejad; mehdi.nourinejad@mail.utoronto.ca
}

Received 11 March 2017; Revised 24 May 2017; Accepted 7 June 2017; Published 6 July 2017

Academic Editor: Richard S. Tay

Copyright (C) 2017 Tyler M. Harris et al. This is an open access article distributed under the Creative Commons Attribution License, which permits unrestricted use, distribution, and reproduction in any medium, provided the original work is properly cited.

\begin{abstract}
Airport curbside congestion is a growing problem as airport passenger traffic continues to increase. Many airports accommodate the increase in passenger traffic by relying on policy and design measures to alleviate congestion and optimize operations. This paper presents a mesoscopic simulation model to assess the effectiveness of such policies. The mesoscopic simulation model combines elements of both microscopic simulation which provides a high level of detail but requires large amounts of data and macroscopic simulation which requires very little data but provides few performance measures. The model is used to simulate scenarios such as double parking, alternative parking space allocation, increased passenger demand, and enforced dwell times at Pearson International Airport in Toronto, Canada. Scenario analysis shows that adjusting model inputs provides reasonable results, demonstrating the value in using this approach to evaluate curbside management policies. The results show that double parking reduces the utilization ratio and the level of service of the outer curbside but cuts down the passenger and vehicle waiting time. Inclement weather conditions reduce the utilization ratio of the inner curbside and the supply of commercial vehicles since it takes them longer to return to the airport. Finally, reducing the allowable parking time at the curbside decreases the average dwell time of private vehicles from 89 seconds to 75 seconds but increases the number of circulating vehicles by $30 \%$.
\end{abstract}

\section{Introduction}

Carefully planned airport curbsides are vital parts of an effectively managed airport. The curbside provides people and vehicles with a means of access and egress to the terminals from the roadway. Curbsides have become congested because airport demand has increased while curbside capacity is limited by the curb length which in turn is limited by the length of the terminal and passenger walking distances. Problems that impact the capacity of a curbside include congestion, long dwell times of pickup vehicles at the curb, double parking, excessive queue lengths for taxi and limousines, and shortages of taxis and limousines. Congestion can be improved through efficient curbside design and effective curbside management policies.

Until 2010, there had been a lack of clear guidelines for analysis of airport curbsides. ACRP Report 40 addressed this shortcoming by developing the Quick Analysis Tool for Airport Roadways (QATAR), a simple macroscopic queuing model for analyzing curbside and weaving sections of airport roadways [1]. The QATAR model uses aggregate functions of queuing theory to define traffic flow behavior. The aggregate nature of the model limits conclusions about the curbside to utilization (ratio of occupied spaces over available spaces) and congestion. Moreover, the aggregate QATAR model is unable to assess the impact of policies that target individual elements of the curbside such as vehicles entering or exiting a parking spot.

An alternative to macroscopic queuing models is microsimulation of individual vehicles. While microsimulation models capture a high level of detail and are able to evaluate many policies, they require substantial data. Moreover, most off-the-shelf microsimulation packages are designed for simulating urban transportation systems and are less well-suited to simulate the unique airport roadway system [2]. Hence, we propose a mesoscopic simulation model which combines elements of both micro- and macrosimulation to capture more measures of effectiveness (MOEs) while requiring a reasonable level of detail. The use of mesoscopic modelling has been advocated in many studies for optimizing network 
traffic flow control measures [3], estimating travel times [4], forecasting real-time bus route states [5], simulating transit operations [6], evaluating emissions impacts [7], cordon pricing [8], link loading [9], and modelling uninterrupted flow facilities [10].

The proposed mesoscopic model uses a Cellular Automata (CA) approach to track individual vehicles at the curbside where detailed vehicle movements are of interest while traffic dynamics everywhere else are represented as aggregate functions. The mesoscopic simulation model is developed for the Terminal 1 arrivals level curbside of Pearson International Airport to assess policy scenarios. With reasonable modifications, the model can be applied to other case studies as well. The characteristics of the arrival and departure curbsides, such as the peak periods, driver and passenger behavior, dwell times, and space allocation, differ considerably [1]. The presented model focuses on the arrivals curbside because curbside challenges at the arrivals level are considerably greater than the departures level.

The remainder of this paper is organized as follows. Section 2 provides a review of previous studies on airport curbside management, simulation, and relevant applications of CA models. Section 3 describes the simulation model, assumptions, MOEs, and the model limitations. In Section 4, a scenario analysis is performed in which the model is used to analyze four different scenarios. Section 5 presents the conclusions.

\section{Literature Review}

The following literature review focuses on airport curbside management, curbside simulation, and CA models.

\subsection{Airport Curbside Management}

2.1.1. Curbside Management Policies. Fisher [1] provides a comprehensive summary of measures for improving curbside operations as part of a cohesive guideline for analyzing airport curbsides and terminal area roadways. The measures include physical improvements and operational measures. Physical improvements, such as widening or lengthening the roadway, providing alternative pickup/drop-off areas, and constructing additional curbside levels, require substantial financial investment and space. Operational measures manage demand at the curbside by improving the public transit mode share, developing offsite facilities including cell phone and park-and-fly lots, increasing enforcement of pickup vehicle dwell times at the curbside, reallocating curbside spaces, and improving commercial vehicle operations.

Focusing on operational measures Budd et al. [11] identify the key issues affecting airport ground access, such as varying requirements for different groundside users, environmental issues such as curbside idling, and increased demand with the rise of low cost carriers. The study examines the policy response to the issues and the resulting impact of the response at airports, focusing on improving the mode share of public transit and nonmotorized modes, increased use of technology, and vehicle parking facilities. Wong and Baker
[12] focus more specifically on rail transportation as a means to reduce curbside emissions and consider policies of US airports with regard to improving the public transportation mode share. Their study demonstrates that many busy US airports do not have policies in effect to encourage increases in the public transportation mode share and provides a case study of an airport with a transit-first policy. Kamga et al. [13] provide a review of taxicab dispatch systems deployed at major airports and illustrate how technology and changes in management strategies can help improve commercial vehicle operations at JFK International Airport and other similar airports.

2.1.2. Airport Curbside Simulation. Most of the research on curbside management focuses on real world applications of curbside simulation. Tunasar et al. [14] develop a discrete event simulation model for the curbside at the AustinBergstrom International Airport. The model uses a CA approach and a set of rules to simulate pedestrian and vehicle behavior, providing a means for scenario analysis for both the arrivals and departures curb at the airport. While not validated with observed data, the model is used to address issues with regard to curbside space allocation at the airport. The model does not provide performance measures for commercial vehicle operations (e.g., taxis and limousines).

Bender and Chang [15] use discrete event simulation modelling for the McCarran International Airport curbside. The model uses both aggregate behavior and distributions of population behavior to simulate the curbside. The movement of vehicles is performed at an aggregate level while characteristics such as dwell times are individually simulated for each vehicle. The model is successfully validated with observed data. The model is very complex with extensive inputs and more resembles a microscopic model than a mesoscopic model. However, it successfully demonstrates the use of mesoscopic simulation techniques for analysis of an airport curbside.

There are four known microscopic simulation models that cater to the airport groundside. Duncan and Johnson [2] present the Leigh Fisher Associates Curbside Traffic Simulation (LFACTS) model. The model assumes stochastic demand and vehicle speed and uses rule-based dynamics to control and define travel behavior for each individual vehicle, allowing them to interact with other elements in the system. The model is applied to several real world airports to analyze the impact of operational changes to the curbside. Beyond the LFACTS model, three other proprietary microscopic simulation models cater directly to the airport groundside: ALPS, TRACS, and VISSIM.

Fisher [1] developed the QATAR model which is a macroscopic simulation model that is used to approximate curbside congestion and utilization of parking spaces using aggregate functions. The model represents the parking spots within the curbside area as a series of servers and vehicles as the queue. It assumes infinite calling population, steady state system, Poisson vehicle arrivals, and exponential service times. 
2.2. Cellular Automata Model. A variety of CA modelling approaches has been used to simulate traffic flow. Maerivoet and De Moor [16] provide an in-depth review for each of these models including Wolfram's Rule 184, which forms the basis of many CA models. This model represents the system as a linear row of cells where the current cell being evaluated is denoted as the $i$ th cell. The cells immediately preceding and succeeding the $i$ th cell are defined as the neighborhood of that cell. In the Rule 184 model, the state of the $i$ th cell ( 1 for occupancy and 0 for vacancy) in the next time space is based on its neighborhood in the current time space. In terms of traffic simulation models, the model can be defined with two rules. The first rule determines the speed of the vehicle where the velocity is defined as the minimum of either one cell/time step or the time gap between the vehicle and the succeeding vehicle. The second rule advances the vehicles in the system by updating each cell based on the velocity. The outcome of the Rule 184 model is a fully deterministic system with no randomness.

The most widely employed algorithms are derived from the probabilistic NaSch model, proposed by Nagel and Schreckenberg [17], and derived from the Rule 184 model. In the NaSch model, the roadway is represented as a onedimensional array with a length $L$ where each cell represents 7.5 meters. Each of these cells can either be occupied by one vehicle or be empty. The model represents the position, velocity, and distance to the preceding vehicle for the $i$ th vehicle at time $t$. The model follows four rules for updating the position of vehicles at each time step which involve acceleration, braking, randomization, and vehicle motion. The model is able to simulate several characteristics of traffic flow such as traffic congestion but its randomization can result in instability causing artificial congestion even at low densities. Nagel and Schreckenberg [17] demonstrate a more stable model where the randomization only applies to vehicles that encounter congestion allowing vehicles in freeflow conditions to maintain velocity.

Rickert et al. [18] examine the application of the NaSch principles to a two-lane model. This model allows vehicles to have different desired velocities and uses macroscopic rules for the changing of lanes to achieve desired velocity. It follows a basic process where a vehicle looks ahead for obstructions (other vehicles) and looks at the other lane to determine if there is space. If all conditions are met, the vehicle performs a lane change into the other lane. This work is further expanded by Wagner et al. [19] who propose a set of lane changing rules that take into account the fact that vehicles making a lane change should consider following vehicles in the target lane among other improvements.

The CA model has also been applied to modelling the dynamics of both vehicle and passenger flow in various contexts. Application of the CA model includes simulating traffic breakdowns in the presence break light technologies [20], modelling the impact of communication delay on railway traffic flow [21], analyzing lane changing rules [22], simulating bus routes [23], simulating heterogeneous traffic in work zones [24], modelling signal controlled traffic streams [25], and analyzing the equivalence between CA models and kinematic wave theory [26].
2.3. Using the Cellular Automata Model for Curbside Management. Very little research has applied mesoscopic simulation models for the airport curbside. This is despite an interest among several airport groundside managers for a simulation model that requires minimal inputs and provides numerous performance measures for evaluation of curbside management policy scenarios (a brief email survey was conducted in which several groundside managers were contacted and asked to provide information regarding curbside simulation at their airport. Of the four that responded, three indicated a level of interest in a mesoscopic simulation model that requires minimal inputs while providing numerous outputs). The CA model provides an approach that can replicate the aggregate flow of vehicles at the curbside while tracking individual elements. The model can be built using some of the basic algorithms outlined in the Rule 184 model to control the forward motion of vehicles and the NaSch two-lane model to control the movement of vehicles between lanes. Additional algorithms are needed to represent parking at the curbside. This research attempts to improve the traffic dynamics of previous models by connecting the processes for different elements of the simulation and by utilizing the model to assess various policy scenarios. The model addresses gaps in previous models by representing commercial vehicles (taxis and limousines) as a closed queue system with a limited vehicle supply.

\section{Model}

The model is developed for the arrivals curbside level at Pearson International Airport Terminal 1 in Toronto, Canada. Pearson International Airport is the largest and busiest airport in Canada with over 450,000 flights and over 44 million passengers annually. Over 75 passenger airlines offer flights from Pearson's two terminals to over 180 destinations around the world. On the groundside, Terminal 1 has three roadway levels, each with parallel curbsides having an estimated length of 450 meters. Approximately 65,000 inbound vehicle trips are made each day with 82 percent of those trips travelling to the main terminal areas to access the curbside or parking facilities [27].

The model is comprehensive enough to be used for other airports as well if modified appropriately. The airport arrivals curbside layout consists of a pickup area and a circulation road as shown in Figure 1. In the proposed model, the pickup area is simulated in detail and the circulation road is macrosimulated.

On the arrivals' level pickup area, there are two parallel curbs. The inner curb is limited to taxis and limos that are contracted by the airport, shuttles for remote parking lots (Park'N Fly), and Airport Express buses, while the outer curb is used by private vehicles. Vehicles enter the pickup area at the domestic side of the terminal and exit from the international side. In order to capture a higher level of detail at the pickup area, a CA simulation is used where the pickup area roadway is broken down into a two-dimensional array with individual cells that are 9 meters in length and 3.7 meters in width. The model uses 9 meters instead of 7.5 meters as 


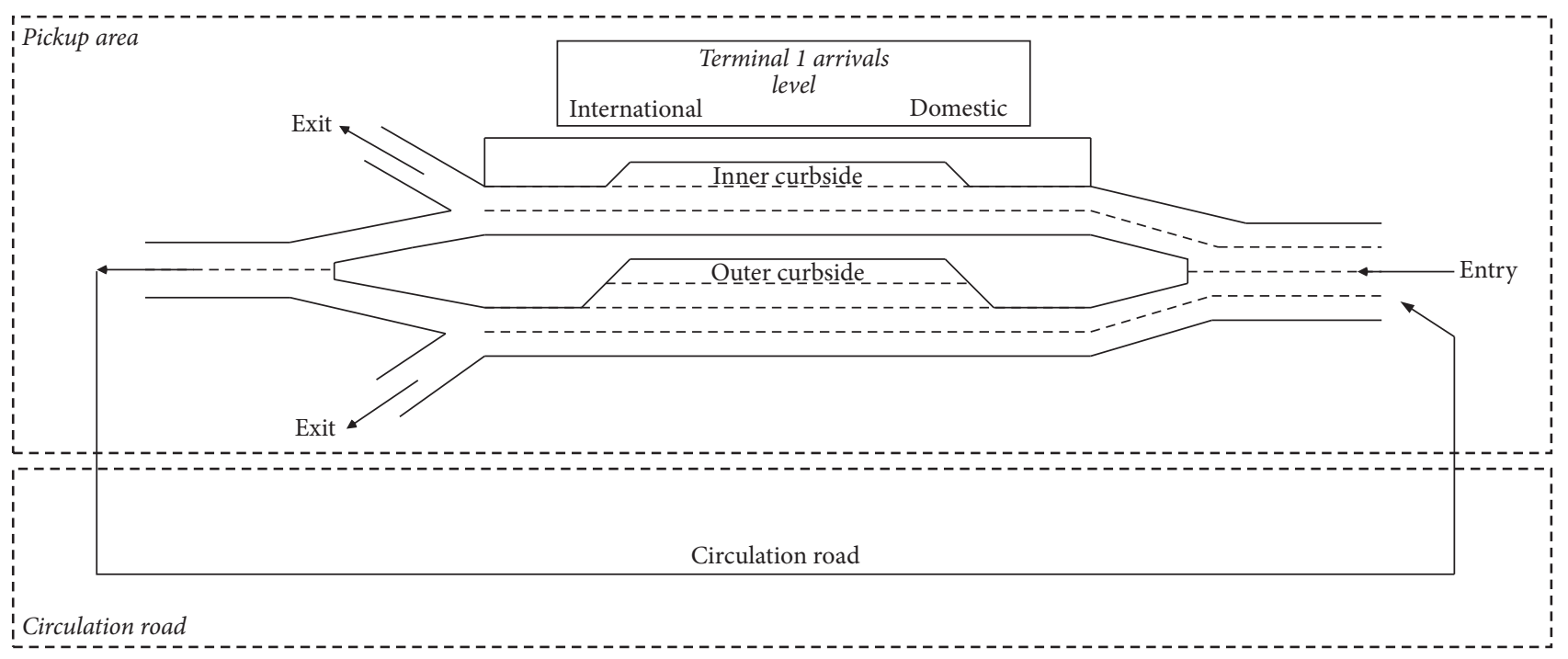

FIgURE 1: Curbside layout for the model.

typically seen in CA models because the 9 meters simplifies the representation of a vehicle velocity of 9 meters per second, or approximately 30 kilometers per hour. Each cell within the array contains a numeric value that is associated with one particular state. At each time step of the simulation, the state of each cell is iteratively updated through the processes described below. There are 23 possible states for each cell in the model, each representing different vehicle and location properties. For example, a cell that has a passenger vehicle with only a driver has a state of 1 while a passenger vehicle with a driver and passenger has a state of 2. Similarly, a taxi without a passenger has a state of 3 while a taxi with a passenger has a state of 4 . Unoccupied parking spaces for passenger vehicles, taxis, and limos have a state of 7,8 , and 9 , respectively, and 0 indicates a roadway cell with no vehicle. In comparison to the pickup area, the details of the traffic dynamics on the circulation road are less important. Hence, the circulation road is considered a deterministic queue. The remainder of this section outlines all aspects of the model including assumptions, model inputs, traffic dynamics and processes, performance measures, limitations, and the graphical user interface.

3.1. Assumptions. The model assumes constant speed of 30 kilometers per hour for all vehicles travelling through the curbside system. Vehicles are assumed to move at a faster speed on the circulation road. The model assumes stochastic behavior for certain processes and properties. The processes for generating vehicles and passengers, parking spot selection, crosswalk choice, loading time, and commercial vehicle travel time are stochastic. This is further explained in Sections 3.3.1-3.3.5.

3.2. Model Inputs. The model requires three types of parameters: constant parameters, estimated distributions of model components, and hourly parameters. Constant parameters remain the same for the entire duration of the simulation.
The parameters that relate to the arrivals level pickup area are part of the model microsimulation while the parameters that relate to areas outside the arrivals level pickup area are part of the model macrosimulation. These parameters include the following:

Beginning/ending time step: the time of day at which the simulation begins/ends.

Quantity of taxis/limos: the total number of taxis and limos available to service passengers that are arriving at the airport.

Maximum dwell time: the maximum time a private vehicle can be parked at the curbside before an enforcement officer requests the vehicle to vacate.

Average passengers per group/vehicle: number of passengers travelling as a group in the same vehicle.

Percentage of through vehicles: the percentage of vehicles that travel through the curbside area without stopping at the curb. These vehicles using the curbside roadway to access other area of the airport and vehicles that are unfamiliar with the airport and are in the wrong area.

Length and speed of circulation road: the length and speed of the circulation road are used to determine how long a vehicle remains on the circulation road.

Double parking: whether or not double parking is permitted on the curbside.

Minimum utilization ratio for double parking: the utilization ratio at which point vehicles begin double parking if double parking is allowed and the required conditions are met. 
The following parameter distributions are needed to simulate the stochastic evolution of the simulation:

Vehicle loading times: the time it takes for a pickup vehicle to load its passenger before it can depart the curbside area.

Crosswalk duration: the time it takes for a passenger to cross the inner roadway to the outer curbside.

Commercial vehicle travel time: the total round-trip travel time for a commercial vehicle (taxi or limo) from the airport curbside to the passenger destination and back to the airport.

Hourly parameters are those that vary hourly. The model assumes that there is a linear change in such parameters from one hour to the next. These parameters include the following:

Passenger arrival rate: the number of passengers arriving at the airport terminal curbside at each hour.

Vehicle mode share: the percentage of arriving passengers that use each available transportation mode to leave the airport.

Domestic/international passenger split: the percentage of arriving passengers at each hour that are on a domestic flight versus an international/trans-border flight.

3.3. Traffic Dynamics and Model Processes. The simulation model consists of processes such as vehicle and passenger generation, vehicle movement, and parking. These processes consist of several subprocesses. This section contains details regarding the main processes used to operate the simulation model.

3.3.1. Vehicle Generation. The vehicle generation process determines at each time step if a new vehicle of each vehicle type is generated and what lane it uses to enter the system. The model includes private vehicles, taxis, limos, and through vehicles. Let us denote the set $T=\{1, \ldots, t, \ldots,|T|\}$ as the set of time steps in hour $T$. For private vehicles, let $p_{v}^{t}$ denote the probability that a pickup vehicle enters the curbside at time $t \in T$, let $m_{v}^{T}$ denote the mode share of private vehicles at hour $T$, let $P^{T}$ be the hourly passenger arrival rate at hour $T$ per curbside, and let $g$ be the average number passengers per vehicle. Hence, we have

$$
p_{v}^{t}=\frac{m_{v}^{T} \cdot\left(P^{T} / g\right)}{3600} .
$$

Using (1), a Monte Carlo simulation is set up to model the flow of pickup vehicles at the pickup area. In the Monte Carlo simulation, a separate random real number within the domain $[0,1]$ is generated at each time step $t$. If the random number is lower than $p_{v}^{t}$, a pickup vehicle is generated. If the random number is higher than $p_{v}^{t}$, no pickup vehicles are generated at time $t$. In (1), $p_{v}^{t}$ is practically never above one because the model has a maximum capacity of one vehicle per second generated. Precisely, the vehicle generation process resembles a Bernoulli number generator. Given that each Bernoulli generation is independent of the next, the entire pickup vehicle generation procedure becomes a Poisson process. The process for through vehicles (i.e., vehicles that only travel the road with their destination outside the boundaries of the analyzed system) is very similar to that of private vehicles where the probability is determined and compared with a randomly generated number. However, the mode share $m_{v}^{T}$ is replaced with the percentage of total vehicles that are through vehicles. As a potential future improvement, the percentage of through vehicles could be adopted as a variable parameter to demonstrate how airports could benefit from improved curbside wayfinding to decrease the percentage of vehicles entrances to wrong areas.

All commercial vehicles (i.e., taxi and limousines) upon their arrival to the airport have to enter the commercial vehicle holding area (CVHA). The CVHA is a parking facility, which is less than a kilometer away from arrivals terminal. The objective of the CVHA is to keep commercial vehicles away from the curbside until they are needed to better manage curbside congestion. Vehicles at the CVHA are chosen in a FIFO (first in, first out) fashion to drive to the pickup area; that is, the first vehicle that arrives at the CVHA is the first to be dispatched to the curbside. To simulate commercial vehicle dispatch dynamics, the model first determines how many empty spaces are available at time $t$ at the pickup area and how many vehicles are already dispatched to the pickup area but have not yet arrived there. If the difference between empty spaces and en-route vehicles is greater than zero, then a new vehicle is dispatched to the pickup area. Because there is a finite fleet of commercial vehicles available, a new vehicle is dispatched to the pickup area if there is a vehicle available in the CVHA. Figure 2 illustrates the details of the commercial vehicle dispatch operations. As illustrated, the vehicles are randomly assigned to lane 1 or 2 in equal proportions. As commercial vehicles exit the system, they are assigned a return time to the airport. The algorithm checks the return time for each vehicle that has exited the system and if the current time step matches with the return time, the CVHA supply for that vehicle type is increased by one. This allows commercial vehicles to be represented as a finite supply.

3.3.2. Passenger Generation. Domestic and international passenger arrivals for each vehicle type are generated at each time step. The probability that a domestic or international passenger for vehicle type $n$, where $n=x$ for taxis, $n=l$ for limos, and $n=v$ for passenger vehicles, reaches the arrivals curb of the airport at time $t$ of hour $T$ is $p_{\mathrm{dn}}^{t}$ and $p_{\mathrm{in}}^{t}$, respectively, for $t \in T$. By denoting the ratio of the domestic and international share of passengers at hour $T$ by $s^{T}$ and $1-s^{T}$, respectively, we have

$$
\begin{aligned}
p_{\mathrm{dn}}^{t} & =\frac{s^{T} \cdot m_{n}^{T} \cdot\left(P^{T} / g\right)}{3600} \\
p_{\text {in }}^{t} & =\frac{\left(1-s^{T}\right) \cdot m_{n}^{T} \cdot\left(P^{T} / g\right)}{3600} .
\end{aligned}
$$




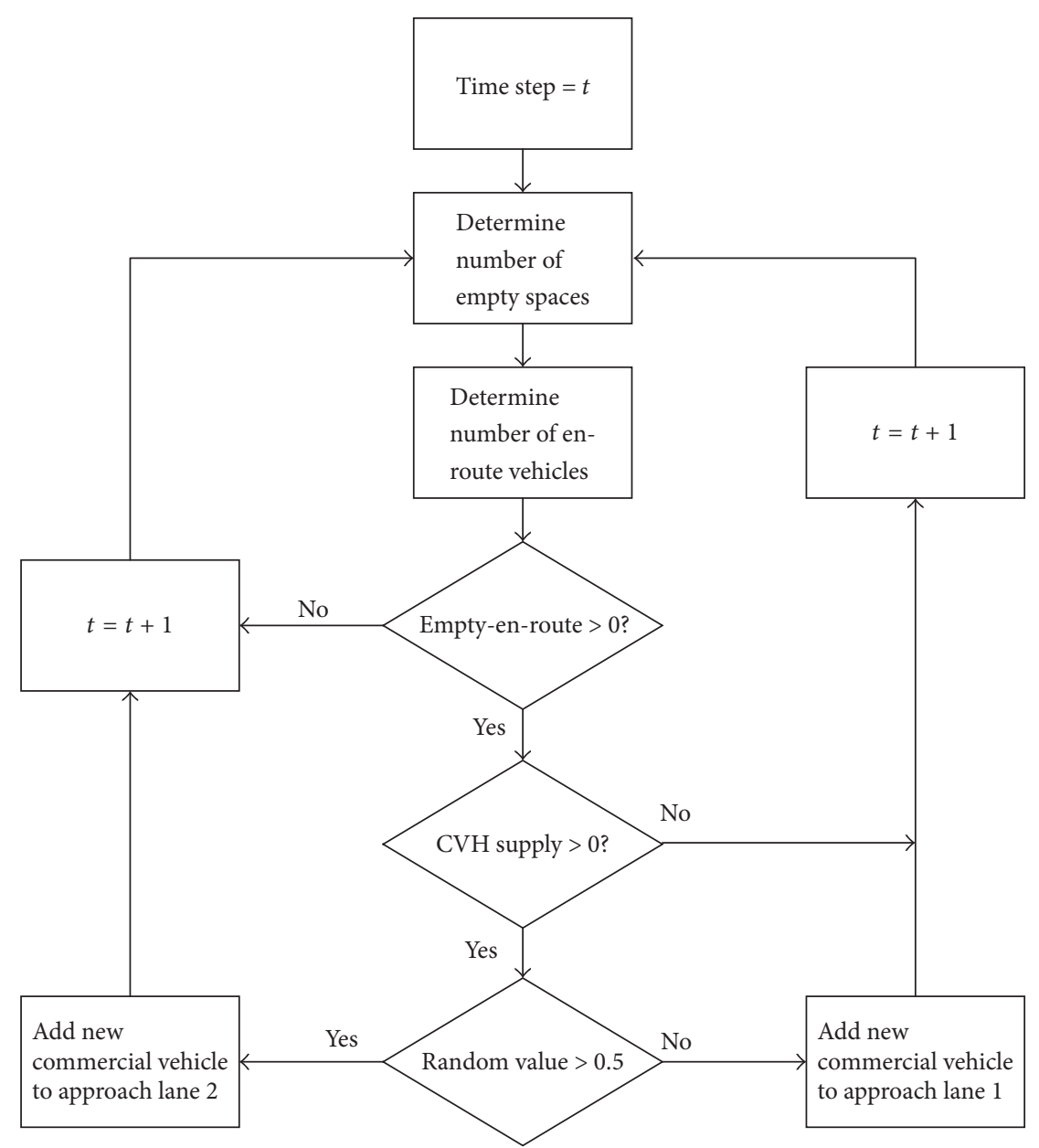

FIgURE 2: Algorithm for generating new taxis and limos.

For each type of commercial vehicle, there exists one specific queue in which passengers wait until they are served. Once a passenger is generated for taxis or limos, the passenger is immediately entered into the respective commercial vehicle queue. For private vehicles, the passengers pass the crosswalk to go from the inner curb to the outer curb. The crosswalk passing process is explained in Section 3.3.5.

3.3.3. Vehicle Movements. Two types of vehicle movements that occur in the model are forward movement and lane change movement. The algorithm for forward movement is obtained from the Rule 184 model [16] in which the status of each vehicle is updated at each time step by looking at the cell ahead. The forward movement algorithm is shown in Figure 3 where $i$ indicates the cell row (lane) number and $j$ indicates the cell column number of the CA model. If the cell ahead is empty, then the vehicle moves forward. If the cell is occupied, then the vehicle does not proceed forward and waits for the next time step.

The two types of lane change movements that occur in the model are discretionary and mandatory movements. A mandatory lane change occurs when the driver needs to position itself in another lane for obligatory vehicle maneuvers such as parking or exiting parking. A discretionary lane change occurs as a result of driver preferences such as speed adjustment or congestion avoidance. Mandatory lane changing is deterministic and occurs at several locations in the model in order for vehicles to move into the correct lane for movement such as entering the curbside, entering and exiting parking spaces, and exiting the system. The approach is shown in Figure 4. In order to perform a lane change, the cell directly to the left or right of the target cell containing a vehicle must be empty. If the cell is empty, the vehicle moves into that cell; otherwise, it remains in the target cell. Discretionary lane changes are stochastic. As pickup vehicles with passengers are leaving the system, they do so by using the first through lane. At each time step, however, there is a defined probability that a vehicle merges into the second through lane. In some cases because of the constant speed assumption, vehicles become trapped in the wrong lane due to the presence of another vehicle in the desired lane. In these cases, where private vehicles enter the curbside and where private vehicles exit the curbside, the model allows the vehicle to hold its position for a single time step, allowing the obstructing vehicle to move ahead by one cell. The vehicle may only hold in a cell for a single time step so if an obstruction is still present, the vehicle must 


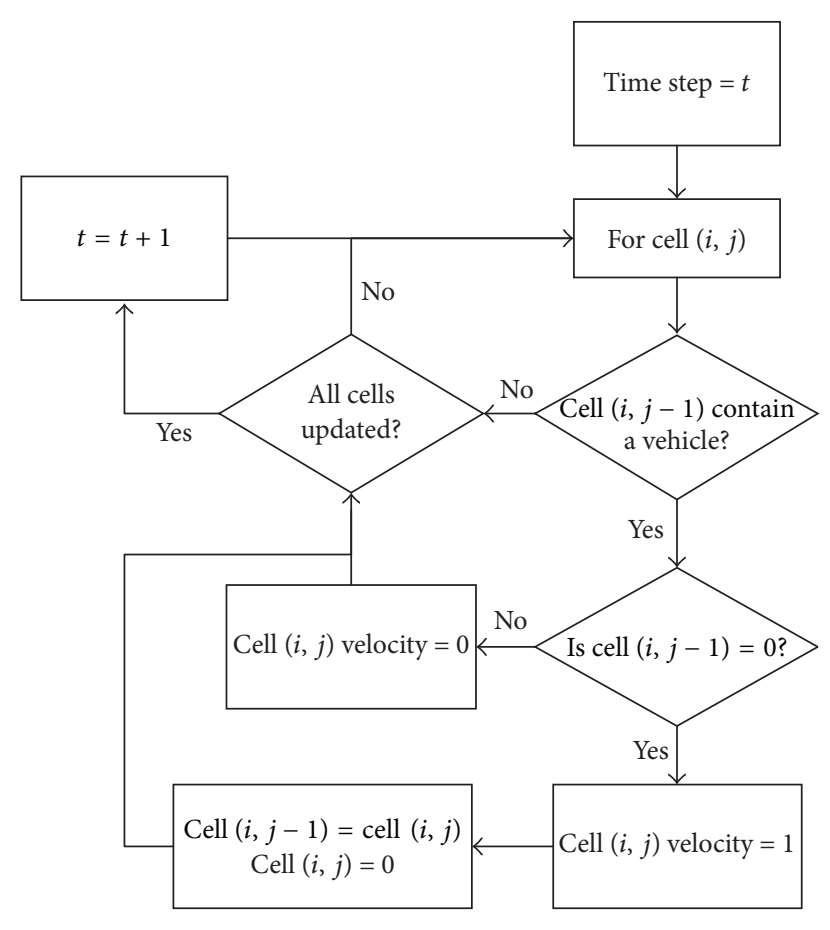

FIgURE 3: Algorithm for forward motion.

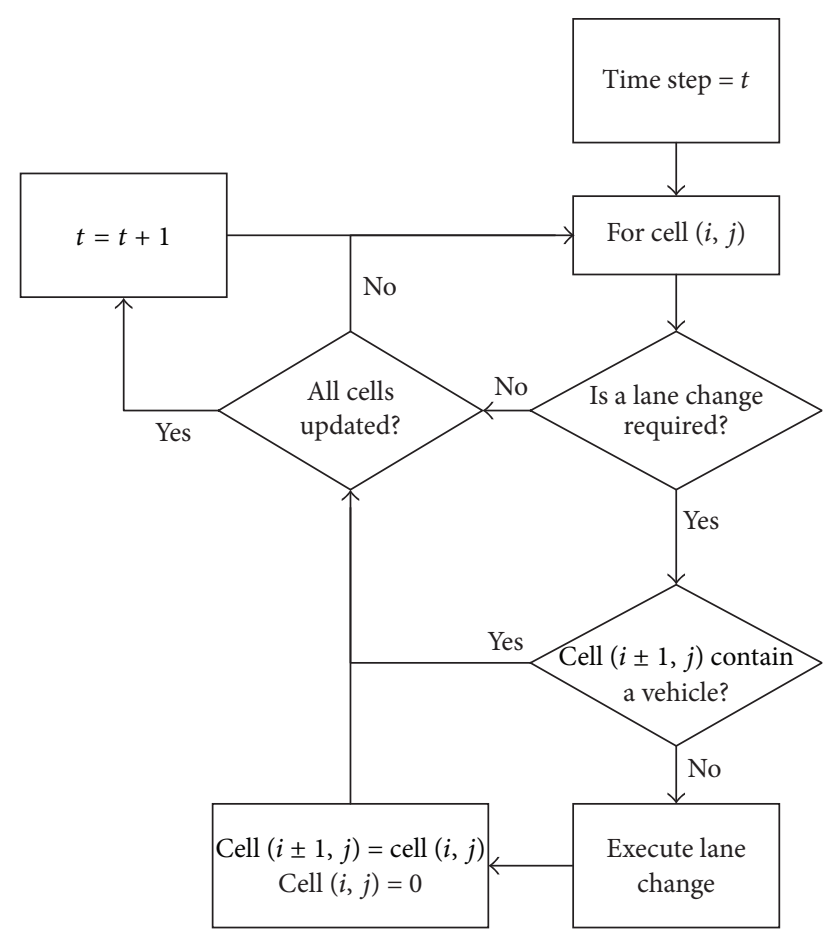

FIGURE 4: Algorithm for mandatory lane changes.

move forward and repeat the process. This effectively allows a vehicle to temporarily cut its speed in half to prevent from becoming trapped.

3.3.4. Vehicle Parking at the Pickup Area. For private vehicles, the process, shown in Figures 5 and 6, begins as soon as the vehicle enters the parking section of the outer curb where the vehicle is randomly assigned to a specific parking spot. Once the vehicle reaches its assigned parking space, if it is unoccupied, the vehicle enters the space and begins queuing for its passenger. Once the passenger loads the vehicle and the departure time (the time at which the vehicle is ready to leave the curbside) is reached, the vehicle exits the parking space and proceeds to exit the system. If the maximum dwell time is reached and the vehicle does not have a passenger, the vehicle exits the pickup area only to return back through the circulation road. As a vehicle enters the circulation road, it progresses forward at a constant speed of approximately $60 \mathrm{~km} / \mathrm{h}$. Once it reaches the end of the circulation road, the vehicle enters the curbside for another attempt at parking. If the vehicle reaches its assigned parking space and the space is occupied, it proceeds until it encounters the first available space beyond its assigned space, unless double parking is allowed.

The process for double parking only occurs if double parking is permitted and the following criteria are met: (i) the utilization ratio is beyond a specified threshold, (ii) there is a passenger waiting to enter a vehicle, and (iii) there are no open spaces in the five downstream parking spaces. Under these conditions, the vehicle double parks and is assigned a departure time based on the loading time for double parked vehicles. Vehicles behind any double parked vehicle proceed forward by changing lanes and passing the double parked vehicle.

For commercial vehicles, the parking process shown in Figure 7 is different. Because commercial vehicles are loaded in a FIFO manner, there is no assignment of parking spaces. Instead, commercial vehicles enter the first available parking space at the inner curb. As the vehicles in the front of the queue are loaded with passengers and exit their space, the vehicles in the rest of the queue move forward, opening spaces at the end of the queue for new vehicles. The commercial vehicles are split into four different queues, international taxis and limos and domestic taxis and limos. As commercial vehicle passengers are generated, they are assigned to one of these vehicle queues at which point the first empty commercial vehicle in each queue is assigned a passenger with a randomly selected loading time. At the vehicle's departure time, the vehicle exits the parking space and proceeds to exit the system.

3.3.5. Crosswalks and Pedestrian Movements. The crosswalk algorithm, shown in Figure 8, allows passengers to cross the inner roadway to access the outer curbside. At Pearson International Airport Terminal 1 arrivals' level the crosswalks and terminal building exits line up and passengers are assumed to use the crosswalk closest to the building terminal exit. As private vehicle passengers are generated, they are randomly assigned to a crosswalk. The passenger is added to the crosswalk queue with a crossing time. The system determines at every time step if there are any passengers using each crosswalk and if so, the crosswalk is indicated as in use and vehicles travelling through the inner curbside stop at the crosswalk until it is free of pedestrians. Passengers using commercial vehicles exit from the terminal at one of the doors and walk to the appropriate commercial vehicle queue 


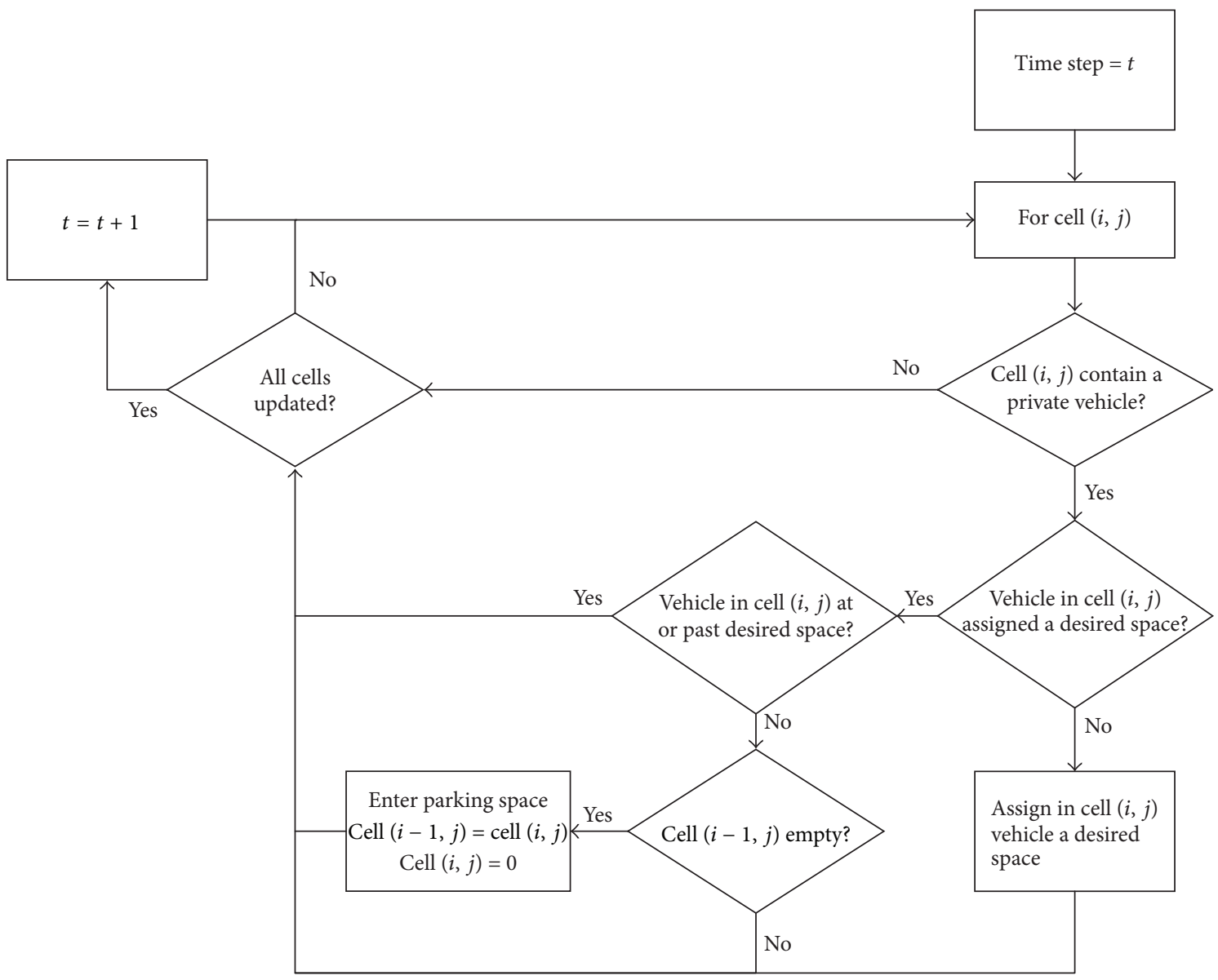

FIGURE 5: Algorithm for private vehicles entering a parking space.

without passing a crosswalk. This is used to determine the access distance for each commercial vehicle passenger.

3.4. Measures of Effectiveness. The MOEs include the utilization ratio, the volume to capacity ratio, dwell times, wait times, and access distance. The utilization ratio expresses the ratio of time that a system is in use and is useful for determining the level of service for the curbside system. The ratio can be expressed as the number of occupied spaces divided by the total number of spaces. A system with a utilization ratio close to 1 indicates a saturated system while a utilization ratio of 0 indicates an empty system. Let $u_{n}^{t}$ and $Q_{n}^{t}$ represent the number of occupied and the total number of spaces at time $t$ for vehicle type $n=v$ for private vehicles, $n=x$ for taxis, and $n=l$ for limos. The utilization ratio is determined at time $t$ for the inner curb (denoted by $\rho_{\text {inner }}^{t}$ ) and the outer curb (denoted by $\rho_{\text {outer }}^{t}$ ) separately as shown in (3) and (4) for commercial vehicles and private vehicles, respectively.

$$
\begin{aligned}
& \rho_{\text {inner }}^{t}=\frac{u_{x}^{t}+u_{l}^{t}}{Q_{x}+Q_{l}} \\
& \rho_{\text {outer }}^{t}=\frac{u_{v}^{t}}{Q_{v}} .
\end{aligned}
$$

For commercial vehicles, a high utilization ratio is desired to reduce waiting time for passengers. On the other hand, a lower ratio for private vehicles is more desirable, indicating that vehicles will not have trouble locating a parking space. The average curbside utilization ratio is determined as the average of the instantaneous utilization over the defined period.

The volume to capacity $(V / C)$ ratio indicates the level of service for the roadway. This ratio, presented in (5), considers the traffic volume $V$ at time $t$ for the preceding 15 minutes and extrapolates the value to 60 minutes. The capacity $C$ of the curbside roadway for time $t$ is a function of the curbside utilization ratio $\rho$ at time $t$, the number of curbside pickup area lanes, and the number of approach lanes to the curbside pickup area as shown in Figure 9 [1]. The $V / C$ ratio obtained for each of the two parallel roadways corresponds to a level of service for that roadway, where a $V / C$ ratio of 0.25 or less is level of service A while a ratio of 1.0 or greater is level of service $\mathrm{F}$

$$
\frac{V}{C^{t}}=\frac{\left[V_{15}^{t} /(15 / 60)\right]}{C_{\rho}^{t}} .
$$

In (5), $V / C^{t}$ is the volume to capacity ratio at time $t, V_{15}^{t}$ is the volume for the prior 15 minutes and $C_{\rho}^{t}$ is the capacity for the utilization ratio $\rho$. 


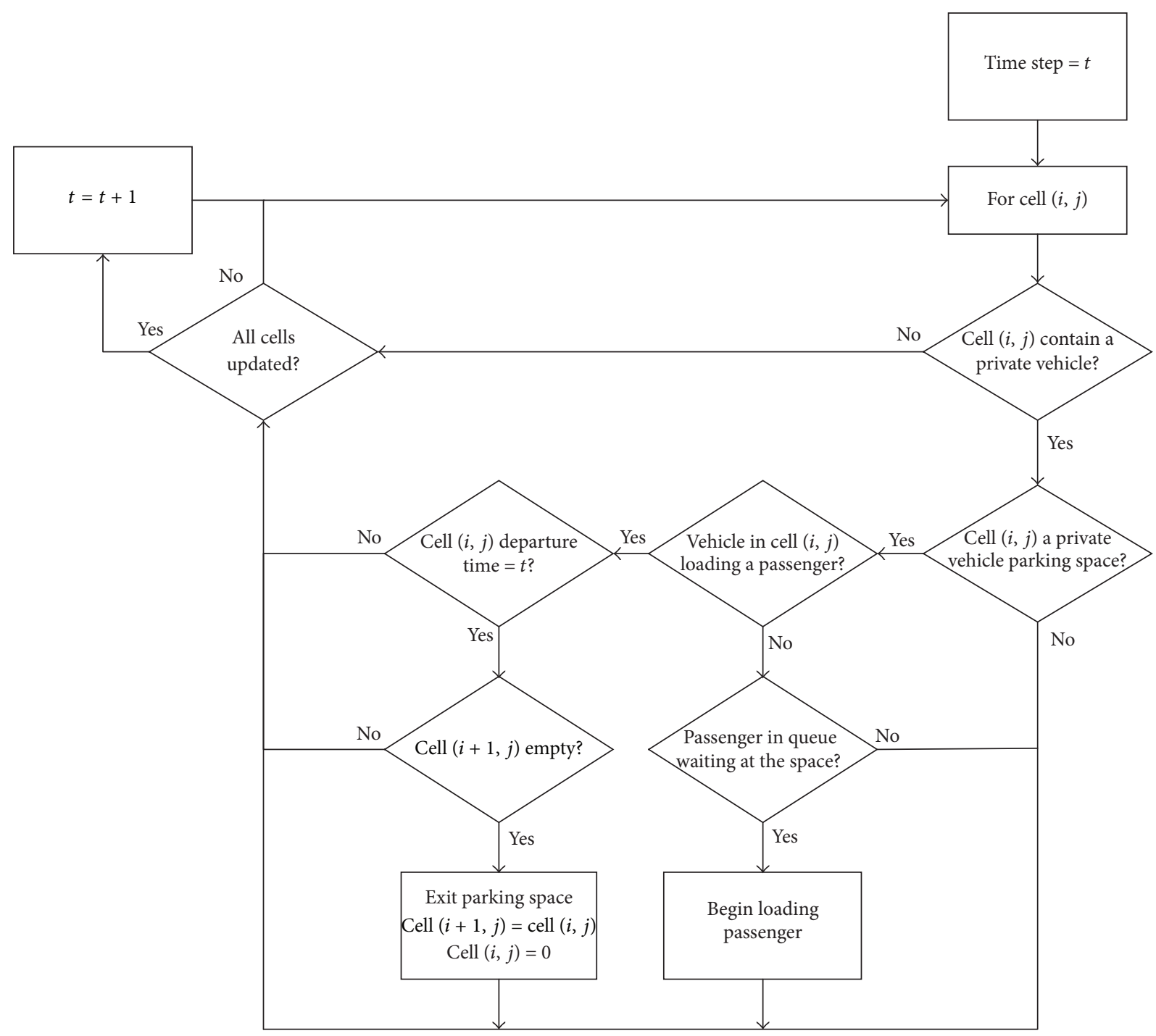

FIGURE 6: Algorithm for private vehicles exiting a parking space.

The dwell time of a vehicle is the total time parked at the pickup area, including the waiting time prior to passenger arrival and loading time. The average vehicle dwell time can affect the utilization ratio and is an important factor for evaluating curbside management policies. Therefore, this MOE is determined for each vehicle type. Let $\bar{D}_{n}^{t}$ be the average dwell time of vehicle type $n$ up to time $t$ where $n=x$ for taxis, $n=l$ for limos, and $n=v$ for passenger vehicles. Let $d_{n}^{t}$ be the total dwell time of all type $n$ vehicles up to time $t$ and let $z_{n}^{t}$ be the cumulative number of type $n$ vehicles that have entered the system up to time $t$. Using $d_{n}^{t}$ and $z_{n}^{t}$, we have

$$
\bar{D}_{n}^{t}=\frac{d_{n}^{t}}{z_{n}^{t}} .
$$

Passenger waiting time is the average time that passengers wait at the pickup area for a vehicle of their desired mode of transportation. This MOE is particularly important for commercial vehicles as there is a strong desire to ensure that passengers do not have to wait long to access a taxi or limo and that drivers are not wasting time parked at the pickup area. For private vehicles, the passenger waiting time is a strong indicator for the level of service at the curbside as high wait times reflect a congested curbside. Let $P W_{n}^{t}$ and $V W_{n}^{t}$ denote the average waiting time of passengers and drivers of vehicle type $n$ up to time $t$, respectively. Let $p w_{n}^{t}$ and $v w_{n}^{t}$ denote the total waiting time of passengers and drivers of vehicle type $n$ up to time $t$, respectively. Let $p_{n}^{t}$ and $v_{n}^{t}$ denote the cumulative number of vehicle type $n$ passengers waiting in queue up to time $t$ and the cumulative number of parked type $n$ vehicles up to time $t$, respectively. The average wait time for passengers and vehicles, shown in (7) and (8) and denoted by $P W_{n}^{t}$ and $V W_{n}^{t}$, respectively, divides the total wait time by the number of passengers or vehicles.

$$
\begin{aligned}
P W_{n}^{t} & =\frac{p w_{n}^{t}}{p_{n}^{t}} \\
V W_{n}^{t} & =\frac{v w_{n}^{t}}{v_{n}^{t}} .
\end{aligned}
$$




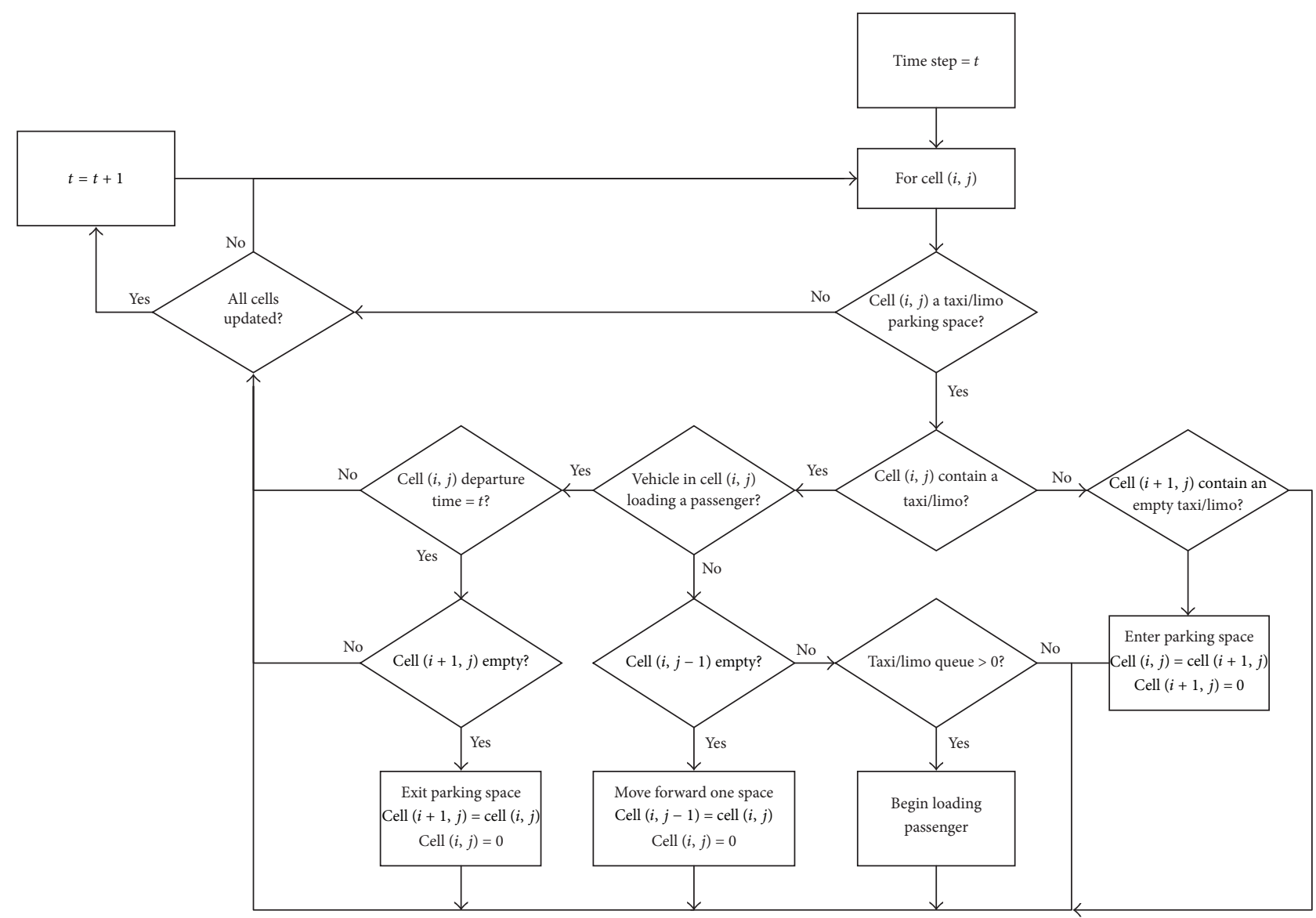

Figure 7: Algorithm for commercial vehicle parking.

The access distance is the distance that passengers walk to access their vehicle. The average access distance is an indicator for the effectiveness of the curbside layout. Let $a_{n}^{t}$ and $A_{n}^{t}$ denote the total and average walking distance of vehicle type $n$ passengers up to time $t$. Hence we have

$$
A_{n}^{t}=\frac{a_{n}^{t}}{p_{n}^{t}} .
$$

The model also tracks other details about the system at time $t$ including the number of each vehicle type in the system, the number of each vehicle type that exited the system, the number of vehicles circulating (queuing), number of taxis and limos in the CVHA, the number of through vehicles, and the number of passengers queuing for a private vehicle. Additional average measures of effectiveness can be constructed from these instantaneous model outputs.

3.5. Equation Variables. For the equations detailed in Sections 3.3 and 3.4 above, Table 1 provides a systematic explanation of the variables used in these equations for reference.

3.6. Graphical User Interface. A graphical user interface (GUI) provides an animation of the CA model over time.
This output represents each vehicle as a small square, where the color of the square coordinates with a vehicle type and current state. For example, the color yellow denotes a taxi, where dark yellow indicates a taxi with a passenger and light yellow indicates a taxi with no passenger. The output shows the vehicles moving through the system along with the performance measures which are also updated at each time step. A snapshot of the GUI is presented in Figure 10.

\section{Scenario Analysis}

With Pearson International Airport expected to approach its capacity by mid-2030s, accommodating increased passenger demand throughout the airport is an ever growing challenge and improved enforcement and double parking at the curbside are two ways that this demand could be accommodated. Also, given the challenge of unpredictable winter storms in Canada and at Pearson International Airport, it is important for planners to understand the impact that inclement weather could have on the curbside and commercial vehicle operations. As such, the model is used to analyze the following four relevant scenarios for Pearson International Airport as against the base case: (i) increased passenger demand, (ii) allowing double parking, (iii) inclement 


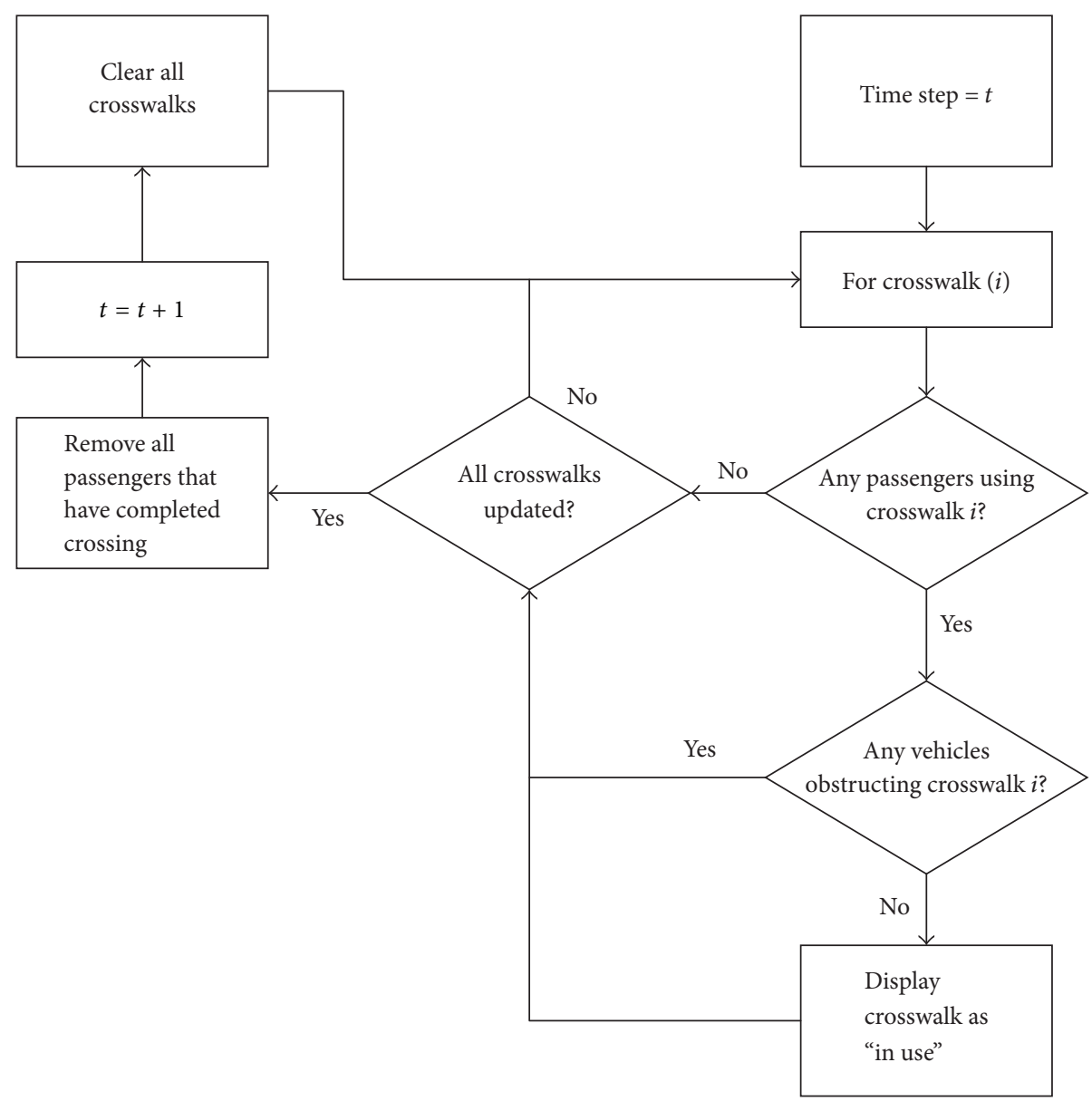

FIGURE 8: Algorithm for crosswalks.

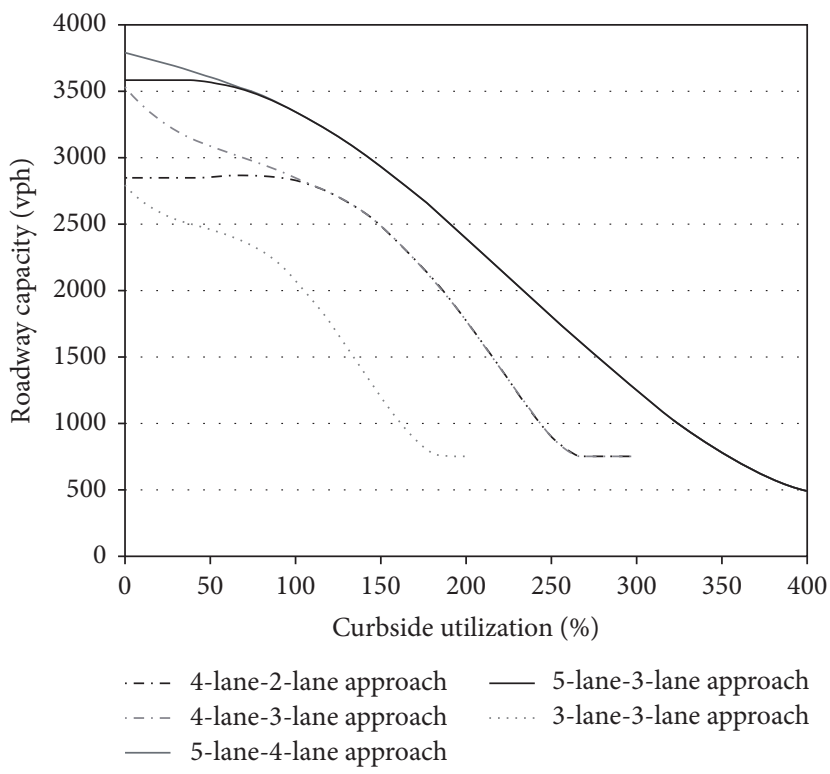

FIgURE 9: Roadway capacity for curbside roads based on utilization ratio [1]. 


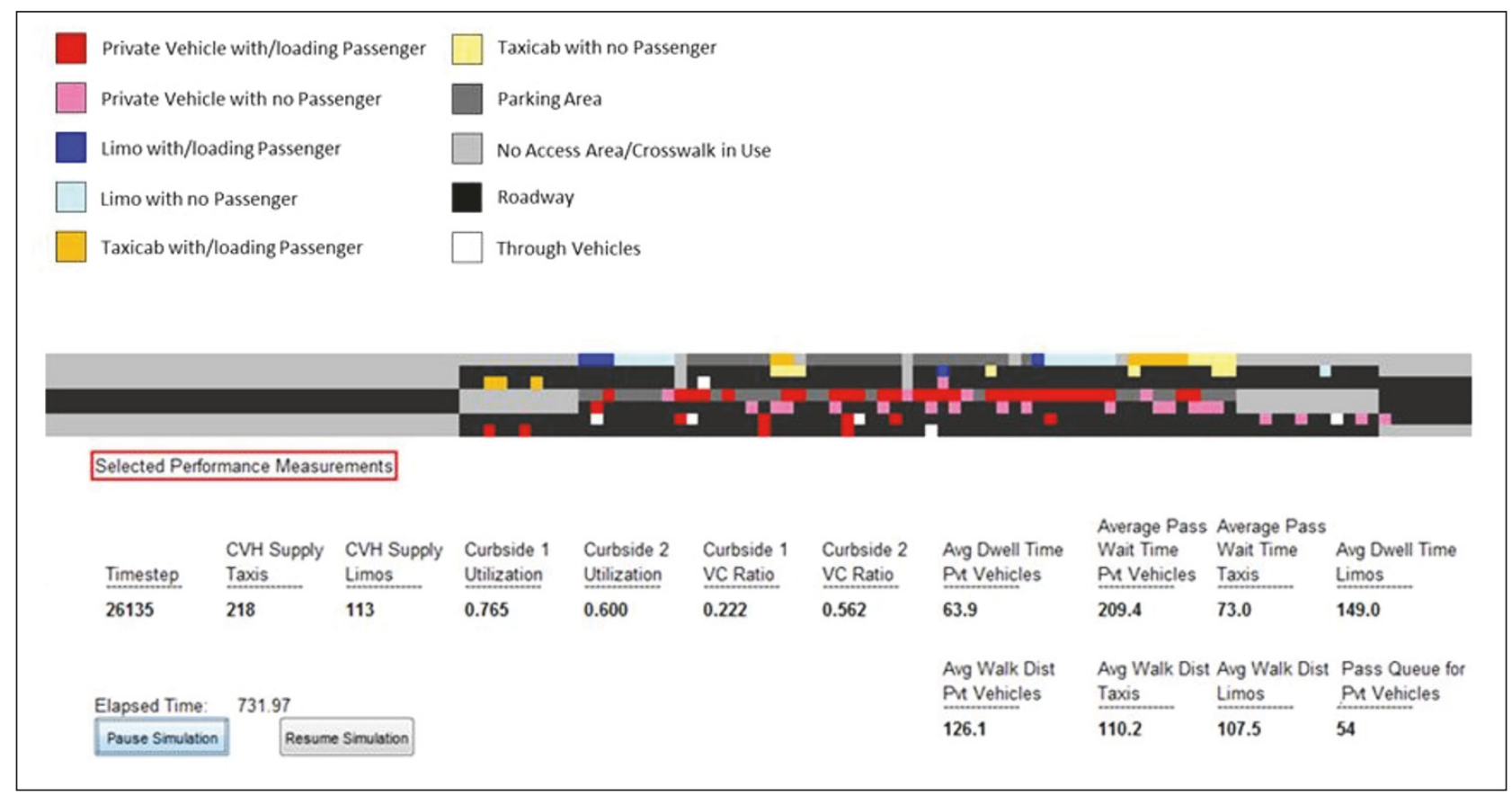

FIGURE 10: GUI simulation output window.

weather conditions, and (iv) increased/improved parking enforcement.

Due to the stochastic nature of the model, each scenario is executed 20 times. Because the system begins in an empty state, the model is run for 1 hour and 15 minutes for each scenario, with the first 15 minutes being the warm-up period of the simulation, which is disregarded when obtaining the MOEs. Welch's $t$-test is then used to compare the mean value of each performance measure from the analyzed scenario to the base case.

4.1. Base Case. The input variables for the base case are listed in Tables 2 and 3. The data in the base case uses assumed values for the user defined inputs. The inputs for the vehicle mode share, passengers per vehicle, and commercial vehicle travel times were estimated using data from the Pearson International Airport Master Plan. The passenger arrival rate and the domestic/international passenger split are based on a passenger volume profile that was estimated using the flight arrivals' schedule for the airport, the aircraft type for each arriving flight, and an assumed load factor. The passenger volume profile for the base case is considered to represent a typical weekday morning peak period hour. The length and speed for the circulation road were estimated using opensourced satellite imagery. The remaining inputs into the base case were assumed based on general observations made at the airport and other sources such as master plans for other airports.

4.2. Increased Passenger Demand. The first scenario reflects an increase in passenger demand of $25 \%$ against the base case.
The results of both the base case and the increased demand scenario are presented in Table 4 and tests of hypothesis are performed to assess which of the MOEs are significantly changed. The last column of the table is bold for measures that significantly differ from the base case with a confidence level of $95 \%$. The most notable unexpected result is that while the passenger waiting time for private vehicles does increase by six seconds, the difference is not found to be statistically significant. However, given that a mean curbside utilization factor of 0.70 (for the outer curbside) corresponds to a level of service $B$, the curbside is not substantially congested. Since a higher passenger arrival rate results in a higher rate for vehicle generation, the passenger waiting time is not significantly different because the system is still adequately able to handle the additional passenger demand. With an even likely higher arrival rate to the point that the curbside system fails, the number of queuing passengers and the average passenger wait time for private vehicles increase significantly. Further simulation with a 50\% increase in passenger demand increases the average passenger wait time to 156 seconds. A $100 \%$ increase in passenger demand further increases the average passenger wait time to 236 seconds.

4.3. Allowing Double Parking. While allowing double parking can drastically increase the parking capacity of the pickup area, double parked vehicles block a lane of vehicle traffic and create congestion. In addition, the double parked vehicles can prevent the adjacent parked vehicle from leaving. For the double parking scenario, the minimum utilization ratio required is set as 0.65 and the 
TABLE 1: Explanation of equation variables.

\begin{tabular}{|c|c|c|c|}
\hline Variable & Classification & Equation \# & Variable explanation \\
\hline$p_{v}^{t}$ & Decision variable & $(1)$ & $\begin{array}{l}\text { Probability that a private vehicle enters the curbside at } \\
\text { time } t \in T\end{array}$ \\
\hline$t$ & Decision variable & $(1),(2)$ & Single time step within hour $T$ \\
\hline$p_{\mathrm{dn}}^{t}$ & Decision variable & $(2)$ & $\begin{array}{l}\text { Probability that a domestic passenger for vehicle type } n \\
\text { reaches the arrivals curb at time } t \text { of hour } T\end{array}$ \\
\hline$p_{\text {in }}^{t}$ & Decision variable & $(2)$ & $\begin{array}{l}\text { Probability that an international passenger for vehicle } \\
\text { type } n \text { reaches the arrivals curb at time } t \text { of hour } T\end{array}$ \\
\hline$\rho_{\text {inner }}^{t}$ & Decision variable & (3), (4) & Utilization ratio for the inner curb at time $t$ \\
\hline$\rho_{\text {outer }}^{t}$ & Decision variable & $(3),(4)$ & Utilization ratio for the inner curb at time $t$ \\
\hline$u_{n}^{t}$ & Decision variable & $(3),(4)$ & Number of occupied spaces for vehicle type $n$ at time $t$ \\
\hline$V_{15}^{t}$ & Decision variable & $(5)$ & Traffic volume $V$ at time $t$ for the preceding 15 minutes \\
\hline$V / C^{t}$ & Decision variable & $(5)$ & Volume to capacity ratio of the roadway at time $t$ \\
\hline $\bar{D}_{n}^{t}$ & Decision variable & (6) & Average dwell time of vehicle type $n$ up to time $t$ \\
\hline$d_{n}^{t}$ & Decision variable & (6) & Total dwell time of all type $n$ vehicles up to time $t$ \\
\hline$z_{n}^{t}$ & Decision variable & (6) & $\begin{array}{l}\text { Cumulative number of type } n \text { vehicles that have entered } \\
\text { the system up to time } t\end{array}$ \\
\hline$P W_{n}^{t}$ & Decision variable & $(7)$ & $\begin{array}{l}\text { Average waiting time of passengers of vehicle type } n \text { up } \\
\text { to time } t\end{array}$ \\
\hline$p_{n}^{t}$ & Decision variable & $(7),(9)$ & $\begin{array}{l}\text { Cumulative number of passengers for type } n \text { vehicles } \\
\text { waiting in queue up to time } t\end{array}$ \\
\hline$p w_{n}^{t}$ & Decision variable & (7) & $\begin{array}{l}\text { Total waiting time of passengers of vehicle type } n \text { up to } \\
\text { time } t\end{array}$ \\
\hline$V W_{n}^{t}$ & Decision variable & $(8)$ & $\begin{array}{l}\text { Average waiting time of drivers of vehicle type } n \text { up to } \\
\text { time } t\end{array}$ \\
\hline$v w_{n}^{t}$ & Decision variable & $(8)$ & $\begin{array}{l}\text { Total waiting time of drivers of vehicle type } n \text { up to time } \\
t\end{array}$ \\
\hline$v_{n}^{t}$ & Decision variable & $(8)$ & $\begin{array}{l}\text { Cumulative number of parked type } n \text { vehicles up to } \\
\text { time } t\end{array}$ \\
\hline$A_{n}^{t}$ & Decision variable & (9) & $\begin{array}{l}\text { Average walking distance of vehicle type } n \text { passengers } \\
\text { up to time } t\end{array}$ \\
\hline$a_{n}^{t}$ & Decision variable & (9) & $\begin{array}{l}\text { Total walking distance of vehicle type } n \text { passengers up } \\
\text { to time } t\end{array}$ \\
\hline$m_{n}^{T}$ & Parameter & $(1),(2)$ & Mode share of vehicle type $n$ at hour $T$ \\
\hline$P^{T}$ & Parameter & $(1),(2)$ & The hourly passenger arrival rate per curbside at hour $T$ \\
\hline$g$ & Parameter & $(1),(2)$ & Number of passengers per vehicle \\
\hline$s^{T}$ & Parameter & $(2)$ & $\begin{array}{l}\text { Ratio of the domestic and international share of } \\
\text { passengers in hour } T\end{array}$ \\
\hline$Q_{n}$ & Parameter & (3), (4) & Total number of spaces for vehicle type $n$ \\
\hline$n$ & Set & (2), (3), (4), (6), (7), (8), (9) & $\begin{array}{l}\text { Vehicle type, where } n=x \text { for taxis, } n=l \text { for limos, and } \\
n=v \text { for passenger vehicles }\end{array}$ \\
\hline$T$ & Set & $(1),(2)$ & $\begin{array}{l}\text { Set } T=\{1, \ldots, t, \ldots,|T|\} \text { as the set of time steps in hour } \\
T\end{array}$ \\
\hline$C_{\rho}^{t}$ & Function & (5) & $\begin{array}{l}\text { The capacity of the roadway as a function of the } \\
\text { curbside utilization ratio } \rho \text { at time } t \text {, the number of } \\
\text { curbside pickup area lanes, and the number of approach } \\
\text { lanes to the curbside pickup area }\end{array}$ \\
\hline
\end{tabular}

mean and standard deviation for double parked vehicle loading time are assumed to be 30 seconds and 5 seconds, respectively.

As expected, allowing vehicles to double park reduces the utilization ratio because some vehicles use the roadway to park instead of the parking spaces. The level of service (i.e., $V / C$ ratio) for the outer curbside decreases as a result of the congestion caused by vehicles double parking. Moreover, a decrease in the passenger wait time, vehicle wait time, and dwell times is expected because double parked vehicles 
TABLE 2: Constant inputs for the base case.

\begin{tabular}{lccccccccccc}
\hline $\begin{array}{l}\text { Pass. arrival } \\
\text { rate } \\
(\mathrm{psgr/hr})\end{array}$ & $\begin{array}{c}\text { P. veh mode } \\
\text { share (\%) }\end{array}$ & $\begin{array}{c}\text { Taxi mode } \\
\text { share (\%) }\end{array}$ & $\begin{array}{c}\text { Limo } \\
\text { mode } \\
\text { share (\%) }\end{array}$ & $\begin{array}{c}\text { Domestic } \\
\text { passenger } \\
\text { split }(\%)\end{array}$ & $\begin{array}{c}\text { Taxis } \\
\text { avail. }\end{array}$ & $\begin{array}{c}\text { Limos } \\
\text { avail. }\end{array}$ & $\begin{array}{c}\text { Max. } \\
\text { dwell } \\
(\mathrm{s})\end{array}$ & $\begin{array}{c}\text { Passengers } \\
\text { per vehicle } \\
(\mathrm{psgr} / \mathrm{veh})\end{array}$ & $\begin{array}{c}\text { Through } \\
\text { vehicles } \\
(\%)\end{array}$ & $\begin{array}{c}\text { Circ. } \\
\text { road } \\
\text { length } \\
(\mathrm{m})\end{array}$ & $\begin{array}{c}\text { Circ. road } \\
\text { speed } \\
(\mathrm{m} / \mathrm{s})\end{array}$ \\
\hline 2800 & 0.55 & 0.17 & 0.07 & 0.65 & 300 & 150 & 300 & 1.3 & 0.2 & 3000 & 16.67 \\
\hline
\end{tabular}

TABLE 3: Variable inputs for base case.

\begin{tabular}{lccccc}
\hline & $\begin{array}{c}\text { Private vehicle loading } \\
\text { time }(\mathrm{s})\end{array}$ & $\begin{array}{c}\text { Taxi loading time } \\
(\mathrm{s})\end{array}$ & $\begin{array}{c}\text { Limo loading } \\
\text { time }(\mathrm{s})\end{array}$ & $\begin{array}{c}\text { Crosswalk walking time } \\
(\mathrm{s})\end{array}$ & $\begin{array}{c}\text { Commercial vehicle travel } \\
\text { time }(\mathrm{s}) \text { from airport to } \\
\text { destination to airport }\end{array}$ \\
\hline Mean & 70 & 50 & 100 & 8 & 3200 \\
Standard deviation & 15 & 15 & 20 & 1 & 2000 \\
\hline
\end{tabular}

load faster and do not wait at the curbside for a passenger to arrive. An average of 47 vehicles double parked in each simulation run, representing $4 \%$ of the total private vehicle traffic. As shown in Table 5, the results are mostly as expected, with the exception of the average wait time for passengers, which is not statistically different from the base case.

4.4. Inclement Weather. Inclement weather, such as a snow storm, often creates problems for airport commercial vehicle operations because of additional demand for commercial vehicles and increased travel times due to poor road conditions. This causes the vehicle supply at the CVHA to become exhausted. This scenario evaluates such an event, where the mode share for taxis and limos is increased by $20 \%$ from 0.17 to 0.20 for taxis and 0.07 to 0.10 for limos, respectively. The private vehicle mode share is decreased by $20 \%$ to 0.44 , and the travel time for commercial vehicles is increased by $20 \%$. It is expected that measures for commercial vehicles would be negatively impacted by the change while measures for private vehicles would be positively impacted or unaffected due to the decreased mode share.

The impact from the inclement weather scenario is as expected as shown in Table 6. The utilization ratio for the inner curbside, the dwell time, vehicle wait time, and the CVHA supply for commercial vehicles all decreased significantly. On the other hand, the passenger wait time for taxis and limos increased significantly. What may not have been expected is the decrease in the number of taxis departing, although this is explained by the increase in travel time for commercial vehicles. Since it takes longer for commercial vehicles to return to the airport, there are fewer taxis available for passengers as the CVHA is replenished at a much slower rate than normal. This results in fewer taxis cycling through the system. The most important factor affecting the measurements is the CVHA supply running out much sooner and vehicles returning to the airport at a slower rate which is consistent with poor weather observations at Pearson Airport.
4.5. Improved Parking Enforcement. Passenger vehicles are allowed to wait up to a maximum allowable time until they are enforced by staff to leave the pickup area. In this scenario, the maximum dwell time is reduced by half from 5 minutes to 2.5 minutes. This would be expected to have an impact on the private vehicle dwell times, the number of vehicles circulating, and the private vehicle waiting time.

The results from reducing the maximum dwell time, reported in Table 7 , show a significant decrease in the average dwell time for private vehicles from 89 seconds to 75 seconds. In addition, the average private vehicle wait time is reduced from 19 seconds to just 6 seconds. The average number of vehicles circulating increases by $30 \%$ although it is not a significantly different change. This can be attributed to a high variance for this performance measure.

\section{Conclusion}

The mesoscopic approach to curbside modelling has the potential to provide airports with a means of evaluating their curbside operations by replicating the aggregate flow of vehicles at the curbside while tracking individual passengers and vehicles at the pickup area. The model simulates the flow of traffic at the curbside, capturing important performance measures such as the utilization ratio, the volume to capacity ratio, wait times, and access distance. The model is multidimensional because it simultaneously represents all key players at the curbside including taxis, limos, and passenger vehicles. The layout of the model is flexible to many terminals with different geometric designs layouts and can be applied to curbsides with single or parallel roadways and of different lengths. The layout is best applied to terminals with separate curbsides for arrivals and departures. For planners, the model provides the advantages of both microand macrosimulation models, as it is much simpler than existing microscopic simulation models, but provides a large number of performance measures that allow for substantial analysis of the curbside. As a result, the model concept could 
TABLE 4: Results for $25 \%$ increase in passenger demand (bold cells indicate that result is significantly different from the base case).

\begin{tabular}{|c|c|c|c|c|c|c|}
\hline Performance measure & Base case mean & $\begin{array}{c}\text { Base case } \\
\text { standard dev. }\end{array}$ & $\begin{array}{l}\text { Scenario } \\
\text { mean }\end{array}$ & $\begin{array}{c}\text { Scenario standard } \\
\text { dev. }\end{array}$ & $\begin{array}{c}\% \text { difference between } \\
\text { means }\end{array}$ & $t$-statistic \\
\hline $\begin{array}{l}\text { Utilization ratio, inner } \\
\text { curbside }\end{array}$ & 0.80 & 0.02 & 0.64 & 0.04 & $-20 \%$ & 16.90 \\
\hline $\begin{array}{l}\text { Utilization ratio, outer } \\
\text { curbside }\end{array}$ & 0.64 & 0.12 & 0.70 & 0.05 & $10 \%$ & 2.39 \\
\hline$V / C$ ratio, inner curbside & 0.26 & 0.01 & 0.28 & 0.01 & $11 \%$ & 10.31 \\
\hline$V / C$ ratio, outer curbside & 0.61 & 0.06 & 0.72 & 0.03 & $17 \%$ & 7.82 \\
\hline Avg. dwell time, p. veh (sec) & 90 & 12 & 80 & 4 & $-12 \%$ & 4.09 \\
\hline Avg. dwell time, taxis (sec) & 134 & 11 & 88 & 11 & $-35 \%$ & 15.54 \\
\hline Avg. dwell time, limos (sec) & 321 & 32 & 241 & 22 & $-25 \%$ & 10.22 \\
\hline $\begin{array}{l}\text { Avg. walk distance, } \mathrm{p} \text {. veh } \\
(\mathrm{m})\end{array}$ & 157 & 3 & 159 & 2 & $1 \%$ & 1.95 \\
\hline $\begin{array}{l}\text { Avg. walk distance, taxis } \\
(\mathrm{m})\end{array}$ & 99 & 4 & 108 & 4 & $9 \%$ & 8.28 \\
\hline $\begin{array}{l}\text { Avg. walk distance, limos } \\
(\mathrm{m})\end{array}$ & 91 & 4 & 87 & 4 & $-5 \%$ & 3.50 \\
\hline Avg. wait time, p. veh (sec) & 133 & 60 & 139 & 26 & $4 \%$ & 0.39 \\
\hline Avg. wait time, taxis (sec) & 2 & 3 & 44 & 25 & $1769 \%$ & 8.24 \\
\hline Avg. wait time, limos (sec) & 1 & 1 & 6 & 7 & $913 \%$ & 3.85 \\
\hline $\begin{array}{l}\text { Avg. vehicle wait time, p. } \\
\text { veh }(\mathrm{sec})\end{array}$ & 19 & 9 & 10 & 4 & $-47 \%$ & 4.41 \\
\hline $\begin{array}{l}\text { Avg. vehicle wait time, taxis } \\
\text { (sec) }\end{array}$ & 84 & 11 & 38 & 10 & $-55 \%$ & 15.52 \\
\hline $\begin{array}{l}\text { Avg. vehicle wait time, } \\
\text { Limos (sec) }\end{array}$ & 221 & 32 & 141 & 22 & $-36 \%$ & 10.27 \\
\hline $\begin{array}{l}\text { Avg. pass. queue length for } \\
\text { p. veh (psgr) }\end{array}$ & 44 & 22 & 57 & 12 & $31 \%$ & 2.69 \\
\hline $\begin{array}{l}\text { Avg. number of circulating } \\
\text { vehicles (veh) }\end{array}$ & 13 & 10 & 10 & 4 & $-24 \%$ & 1.48 \\
\hline $\begin{array}{l}\text { Number of through } \\
\text { vehicles (veh) }\end{array}$ & 376 & 18 & 451 & 19 & $20 \%$ & 14.22 \\
\hline $\begin{array}{l}\text { Avg. number of p. veh in } \\
\text { system (veh) }\end{array}$ & 49 & 13 & 49 & 6 & $-2 \%$ & 0.28 \\
\hline $\begin{array}{l}\text { Avg. number of taxis in } \\
\text { system (veh) }\end{array}$ & 24 & 1 & 21 & 1 & $-11 \%$ & 10.72 \\
\hline $\begin{array}{l}\text { Avg. number of limos in } \\
\text { system (veh) }\end{array}$ & 18 & 0 & 18 & 1 & $-1 \%$ & 1.06 \\
\hline $\begin{array}{l}\text { Total number of p. veh } \\
\text { departed (veh/hr) }\end{array}$ & 1173 & 26 & 1474 & 19 & $26 \%$ & 46.49 \\
\hline $\begin{array}{l}\text { Total number of taxis } \\
\text { departed (veh/hr) }\end{array}$ & 362 & 17 & 388 & 12 & $7 \%$ & 6.15 \\
\hline $\begin{array}{l}\text { Total number of limos } \\
\text { departed (veh/hr) }\end{array}$ & 152 & 14 & 186 & 9 & $22 \%$ & 9.70 \\
\hline $\begin{array}{l}\text { Average number of taxis in } \\
\text { CVHA (veh) }\end{array}$ & 87 & 11 & 52 & 9 & $-40 \%$ & 12.45 \\
\hline $\begin{array}{l}\text { Average number of limos in } \\
\text { CVHA (veh) }\end{array}$ & 60 & 7 & 41 & 7 & $-32 \%$ & 9.67 \\
\hline
\end{tabular}


TABLE 5: Results for double parking scenario (bold cells indicate that result is significantly different from the base case).

\begin{tabular}{|c|c|c|c|c|c|c|}
\hline Performance measure & $\begin{array}{c}\text { Base case } \\
\text { mean }\end{array}$ & $\begin{array}{c}\text { Base case standard } \\
\text { dev. }\end{array}$ & $\begin{array}{l}\text { Scenario } \\
\text { mean }\end{array}$ & $\begin{array}{c}\text { Scenario standard } \\
\text { dev. }\end{array}$ & $\%$ difference & $t$-statistic \\
\hline Utilization ratio, inner curbside & 0.80 & 0.02 & 0.81 & 0.02 & $1 \%$ & 1.77 \\
\hline Utilization ratio, outer curbside & 0.64 & 0.12 & 0.55 & 0.04 & $-14 \%$ & 3.55 \\
\hline$V / C$ ratio, inner curbside & 0.26 & 0.01 & 0.26 & 0.01 & $1 \%$ & 0.52 \\
\hline$V / C$ ratio, outer curbside & 0.61 & 0.06 & 0.66 & 0.08 & $8 \%$ & 2.34 \\
\hline Avg. dwell time, p. veh (sec) & 90 & 12 & 82 & 4 & $-9 \%$ & 3.35 \\
\hline Avg. dwell time, taxis (sec) & 134 & 11 & 136 & 9 & $1 \%$ & 0.59 \\
\hline Avg. dwell time, limos (sec) & 321 & 32 & 331 & 22 & $3 \%$ & 1.31 \\
\hline Avg. walk distance, p. veh (m) & 157 & 3 & 156 & 3 & $0 \%$ & 0.88 \\
\hline Avg. walk distance, taxis (m) & 99 & 4 & 99 & 4 & $0 \%$ & 0.01 \\
\hline Avg. walk distance, limos (m) & 91 & 4 & 90 & 4 & $-1 \%$ & 0.94 \\
\hline Avg. wait time, p. veh (sec) & 133 & 60 & 150 & 41 & $12 \%$ & 1.12 \\
\hline Avg. wait time, taxis (sec) & 2 & 3 & 1 & 1 & $-48 \%$ & 1.91 \\
\hline Avg. wait time, limos (sec) & 1 & 1 & 1 & 1 & $11 \%$ & 0.24 \\
\hline Avg. vehicle wait time, p. veh (sec) & 19 & 9 & 14 & 5 & $-27 \%$ & 2.46 \\
\hline Avg. vehicle wait time, taxis (sec) & 84 & 11 & 85 & 9 & $1 \%$ & 0.46 \\
\hline Avg. vehicle wait time, limos (sec) & 221 & 32 & 232 & 23 & $5 \%$ & 1.43 \\
\hline Avg. pass. queue length for p. veh (psgr) & 44 & 22 & 49 & 15 & $12 \%$ & 1.01 \\
\hline Avg. number of circulating vehicles (veh) & 13 & 10 & 21 & 14 & $53 \%$ & 2.09 \\
\hline Number of through vehicles (veh) & 376 & 18 & 372 & 16 & $-1 \%$ & 0.92 \\
\hline Avg. number of p. veh in system (veh) & 49 & 13 & 50 & 12 & $2 \%$ & 0.21 \\
\hline Avg. number of taxis in system (veh) & 24 & 1 & 24 & 1 & $1 \%$ & 1.95 \\
\hline Avg. number of limos in system (veh) & 18 & 0 & 18 & 0 & $0 \%$ & 0.16 \\
\hline Total number of p. veh departed (veh/hr) & 1173 & 26 & 1180 & 19 & $1 \%$ & 1.09 \\
\hline Total number of taxis departed (veh/hr) & 362 & 17 & 362 & 16 & $0 \%$ & 0.03 \\
\hline Total number of limos departed (veh/hr) & 152 & 14 & 148 & 9 & $-3 \%$ & 1.36 \\
\hline Average number of taxis in CVHA (veh) & 87 & 11 & 88 & 11 & $2 \%$ & 0.53 \\
\hline Average number of limos in CVHA (veh) & 60 & 7 & 63 & 7 & $6 \%$ & 1.80 \\
\hline
\end{tabular}

be a valuable tool for planners to evaluate the traffic demand at the airport curbside, to assess different scenarios that could be applied to manage demand, or to help planners identify and address other problems, such as the layout of the curbside.

Applying the scenario analysis to the model demonstrates that the model is capable of analyzing different policy scenarios to determine the potential impact of the policy application. Overall, the scenario analysis has shown that adjusting the model inputs provides reasonable and helpful results. The results show that double parking reduces the utilization ratio and the level of service of the outer curbside but cuts down the passenger and vehicle waiting time. Inclement weather conditions reduce the utilization ratio of the inner curbside and the supply of commercial vehicles since it takes them longer to return to the airport. Finally, reducing the allowable parking time at the curbside decreases the average dwell time of private vehicles from 89 seconds to 75 seconds but increases the number of circulating vehicles by $30 \%$.

Further work should be focused on improving the flexibility to easily adapt to any type of curbside and improving the model to a point where it can be used by airports to accurately simulate the curbside. The next steps for the model would be 
TABLE 6: Results for inclement weather scenario (bold cells indicate that result is significantly different from the base case).

\begin{tabular}{|c|c|c|c|c|c|c|}
\hline Performance measure & $\begin{array}{c}\text { Base case } \\
\text { mean }\end{array}$ & $\begin{array}{c}\text { Base case standard } \\
\text { dev. }\end{array}$ & $\begin{array}{c}\text { Scenario } \\
\text { mean }\end{array}$ & $\begin{array}{c}\text { Scenario standard } \\
\text { dev. }\end{array}$ & $\%$ difference & $T$-statistic \\
\hline Utilization ratio, inner curbside & 0.80 & 0.02 & 0.57 & 0.05 & $-29 \%$ & 19.71 \\
\hline Utilization ratio, outer curbside & 0.64 & 0.12 & 0.59 & 0.11 & $-8 \%$ & 1.67 \\
\hline$V / C$ ratio, inner curbside & 0.26 & 0.01 & 0.25 & 0.01 & $-2 \%$ & 2.84 \\
\hline$V / C$ ratio, outer curbside & 0.61 & 0.06 & 0.51 & 0.04 & $-17 \%$ & 7.14 \\
\hline Avg. dwell time, p. veh (sec) & 90 & 12 & 93 & 9 & $3 \%$ & 1.05 \\
\hline Avg. dwell time, taxis (sec) & 134 & 11 & 100 & 10 & $-26 \%$ & 11.55 \\
\hline Avg. dwell time, limos (sec) & 321 & 32 & 197 & 23 & $-39 \%$ & 15.59 \\
\hline Avg. walk distance, p. veh (m) & 157 & 3 & 155 & 2 & $-1 \%$ & 2.32 \\
\hline Avg. walk distance, taxis (m) & 99 & 4 & 110 & 5 & $12 \%$ & 9.15 \\
\hline Avg. walk distance, limos (m) & 91 & 4 & 86 & 4 & $-6 \%$ & 4.23 \\
\hline Avg. wait time, p. veh (sec) & 133 & 60 & 142 & 59 & $6 \%$ & 0.51 \\
\hline Avg. wait time, taxis (sec) & 2 & 3 & 48 & 30 & $1925 \%$ & 7.70 \\
\hline Avg. wait time, limos (sec) & 1 & 1 & 37 & 27 & $6086 \%$ & 6.68 \\
\hline Avg. vehicle wait time, p. veh (sec) & 19 & 9 & 23 & 9 & $26 \%$ & 1.93 \\
\hline Avg. vehicle wait time, taxis (sec) & 84 & 11 & 50 & 11 & $-41 \%$ & 11.34 \\
\hline Avg. vehicle wait time, limos (sec) & 221 & 32 & 96 & 23 & $-57 \%$ & 15.79 \\
\hline Avg. pass. queue length for p. veh (psgr) & 44 & 22 & 37 & 17 & $-16 \%$ & 1.28 \\
\hline Avg. number of circulating vehicles (veh) & 13 & 10 & 9 & 6 & $-32 \%$ & 1.81 \\
\hline Number of through vehicles (veh) & 376 & 18 & 382 & 17 & $1 \%$ & 1.09 \\
\hline Avg. number of p. veh in system (veh) & 49 & 13 & 43 & 8 & $-12 \%$ & 2.18 \\
\hline Avg. number of taxis in system (veh) & 24 & 1 & 19 & 1 & $-20 \%$ & 16.92 \\
\hline Avg. number of limos in system (veh) & 18 & 0 & 14 & 1 & $-19 \%$ & 13.29 \\
\hline Total number of $\mathrm{p}$. veh departed (veh/hr) & 1173 & 26 & 935 & 21 & $-20 \%$ & 35.75 \\
\hline Total number of taxis departed (veh/hr) & 362 & 17 & 352 & 12 & $-3 \%$ & 2.54 \\
\hline Total number of limos departed (veh/hr) & 152 & 14 & 184 & 7 & $21 \%$ & 9.77 \\
\hline Average number of taxis in CVHA (veh) & 87 & 11 & 53 & 6 & $-39 \%$ & 13.09 \\
\hline Average number of limos in CVHA (veh) & 60 & 7 & 30 & 4 & $-49 \%$ & 17.50 \\
\hline
\end{tabular}

to address some of the limitations, particularly the matching of passengers to private vehicles entering the system as well as refining and improving other processes. Furthermore, research looking into building the model to be more flexible to different terminals/layouts would be a potential substantial improvement to the model. Beyond improving the actual model itself, future work should also include obtaining actual observed data from the airport that can be used to validate and calibrate the model. In addition, this actual observed data should be used to compare the results of this model with other approaches that may be available to demonstrate and verify the advantages of this model over these other approaches.

\section{Conflicts of Interest}

The authors declare that there are no conflicts of interest regarding the publication of this paper. 
TABLE 7: Results for increased enforcement scenario (bold cells indicate that result is significantly different from the base case).

\begin{tabular}{|c|c|c|c|c|c|c|}
\hline Performance measure & $\begin{array}{c}\text { Base case } \\
\text { mean }\end{array}$ & $\begin{array}{c}\text { Base case standard } \\
\text { dev. }\end{array}$ & $\begin{array}{c}\text { Scenario } \\
\text { mean }\end{array}$ & $\begin{array}{c}\text { Scenario standard } \\
\text { dev. }\end{array}$ & $\%$ difference & $t$-statistic \\
\hline Utilization ratio, inner curbside & 0.80 & 0.02 & 0.80 & 0.02 & $0 \%$ & 0.11 \\
\hline Utilization ratio, outer curbside & 0.64 & 0.12 & 0.59 & 0.09 & $-8 \%$ & 1.66 \\
\hline $\mathrm{V} / \mathrm{C}$ ratio, inner curbside & 0.26 & 0.01 & 0.25 & 0.01 & $-1 \%$ & 0.71 \\
\hline V/C ratio, outer curbside & 0.61 & 0.06 & 0.62 & 0.06 & $1 \%$ & 0.39 \\
\hline Avg. dwell time, p. veh (sec) & 90 & 12 & 75 & 2 & $-17 \%$ & 6.06 \\
\hline Avg. dwell time, taxis (sec) & 134 & 11 & 132 & 10 & $-1 \%$ & 0.53 \\
\hline Avg. dwell time, limos (sec) & 321 & 32 & 324 & 29 & $1 \%$ & 0.36 \\
\hline Avg. walk distance, p. veh (m) & 157 & 3 & 157 & 2 & $0 \%$ & 0.50 \\
\hline Avg. walk distance, taxis (m) & 99 & 4 & 98 & 4 & $-1 \%$ & 0.80 \\
\hline Avg. walk distance, limos (m) & 91 & 4 & 91 & 3 & $0 \%$ & 0.08 \\
\hline Avg. wait time, p. veh (sec) & 133 & 60 & 143 & 48 & $8 \%$ & 0.65 \\
\hline Avg. wait time, taxis (sec) & 2 & 3 & 2 & 3 & $0 \%$ & 0.01 \\
\hline Avg. wait time, limos (sec) & 1 & 1 & 1 & 2 & $53 \%$ & 0.93 \\
\hline Avg. vehicle wait time, p. veh (sec) & 19 & 9 & 6 & 3 & $-70 \%$ & 6.86 \\
\hline Avg. vehicle wait time, taxis (sec) & 84 & 11 & 82 & 10 & $-2 \%$ & 0.57 \\
\hline Avg. vehicle wait time, limos (sec) & 221 & 32 & 224 & 29 & $2 \%$ & 0.39 \\
\hline Avg. pass. queue length for p. veh (psgr) & 44 & 22 & 45 & 18 & $2 \%$ & 0.16 \\
\hline Avg. number of circulating vehicles (veh) & 13 & 10 & 17 & 11 & $31 \%$ & 1.17 \\
\hline Number of through vehicles (veh) & 376 & 18 & 377 & 22 & $0 \%$ & 0.06 \\
\hline Avg. number of p. veh in system (veh) & 49 & 13 & 47 & 13 & $-4 \%$ & 0.52 \\
\hline Avg. number of taxis in system (veh) & 24 & 1 & 24 & 1 & $0 \%$ & 0.03 \\
\hline Avg. number of limos in system (veh) & 18 & 0 & 18 & 0 & $0 \%$ & 0.15 \\
\hline Total number of p. veh departed (veh/hr) & 1173 & 26 & 1171 & 29 & $0 \%$ & 0.29 \\
\hline Total number of taxis departed (veh/hr) & 362 & 17 & 367 & 14 & $1 \%$ & 1.16 \\
\hline Total number of limos departed (veh/hr) & 152 & 14 & 152 & 10 & $-1 \%$ & 0.24 \\
\hline Average number of taxis in CVHA (veh) & 87 & 11 & 87 & 10 & $1 \%$ & 0.20 \\
\hline Average number of limos in CVHA (veh) & 60 & 7 & 61 & 6 & $2 \%$ & 0.69 \\
\hline
\end{tabular}

\section{References}

[1] L. Fisher, ACRP Report 40: Airport Curbside and Terminal Area Roadway Operations, Transportation Research Board, Washington, DC, USA, 2010.

[2] G. Duncan and H. Johnson, "Development and application of a dynamic simulation model for airport curbsides," in The 2020 Vision of Air Transportation-Emerging Issues and Innovative Solutions, pp. 153-164, American Society of Civil Engineers, Reston, Va, USA, 2000.

[3] M. Di Gangi, G. E. Cantarella, R. D. Pace, and S. Memoli, "Network traffic control based on a mesoscopic dynamic flow model," Transportation Research Part C: Emerging Technologies, vol. 66, pp. 3-26, 2016.

[4] M. Dell'Orco, M. Marinelli, and M. A. Silgu, "Bee colony optimization for innovative travel time estimation, based on a mesoscopic traffic assignment model," Transportation Research Part C: Emerging Technologies, vol. 66, pp. 48-60, 2016.

[5] E. Hans, N. Chiabaut, L. Leclercq, and R. L. Bertini, "Real-time bus route state forecasting using particle filter and mesoscopic modeling," Transportation Research Part C: Emerging Technologies, vol. 61, pp. 121-140, 2015.
[6] T. Toledo, O. Cats, W. Burghout, and H. N. Koutsopoulos, "Mesoscopic simulation for transit operations," Transportation Research Part C: Emerging Technologies, vol. 18, no. 6, pp. 896908, 2010.

[7] X. Zhou, S. Tanvir, H. Lei et al., "Integrating a simplified emission estimation model and mesoscopic dynamic traffic simulator to efficiently evaluate emission impacts of traffic management strategies," Transportation Research Part D: Transport and Environment, vol. 37, pp. 123-136, 2015.

[8] I. Kristoffersson, "Impacts of time-varying cordon pricing: validation and application of mesoscopic model for Stockholm," Transport Policy, vol. 28, pp. 51-60, 2013.

[9] H. B. Celikoglu and M. Dell'Orco, "Mesoscopic simulation of a dynamic link loading process," Transportation Research Part C: Emerging Technologies, vol. 15, no. 5, pp. 329-344, 2007.

[10] Y.-C. Chiu, L. Zhou, and H. Song, "Development and calibration of the Anisotropic Mesoscopic Simulation model for uninterrupted flow facilities," Transportation Research Part B: Methodological, vol. 44, no. 1, pp. 152-174, 2010.

[11] T. Budd, S. Ison, and T. Ryley, "Airport surface access in the UK: a management perspective," Research in Transportation Business and Management, vol. 1, no. 1, pp. 109-117, 2011. 
[12] D. Wong and D. Baker, "Airport ground transportation policies and the future of rail connections at US airports," in Proceedings of the Transportation Research Board 92nd Annual Meeting, Washington, DC, USA, January 2013.

[13] C. Kamga, A. Conway, A. Singhal, and A. Yazici, "Using advanced technologies to manage airport taxicab operations," Journal of Urban Technology, vol. 19, no. 4, pp. 23-43, 2012.

[14] C. Tunasar, G. Bender, and H. Yung, "Modeling curbside vehicular traffic at airports," in Proceedings of the 30th Conference on Winter Simulation (WSC '98), pp. 1113-1118, IEEE Computer Society Press, Washington, DC, USA, December 1998.

[15] G. G. Bender and K. Y. Chang, "Simulating roadway and curbside traffic at Las Vegas McCarran International Airport," IIE Solutions, vol. 29, no. 11, pp. 26-30, 1997.

[16] S. Maerivoet and B. De Moor, "Cellular automata models of road traffic," Physics Reports, vol. 419, no. 1, pp. 1-64, 2005.

[17] K. Nagel and M. Schreckenberg, "A cellular automaton model for freeway traffic," Journal de Physique I, vol. 2, no. 12, pp. 22212229, 1992.

[18] M. Rickert, K. Nagel, M. Schreckenberg, and A. Latour, "Two lane traffic simulations using cellular automata," Physica A: Statistical Mechanics and its Applications, vol. 231, no. 4, pp. 534550, 1996.

[19] P. Wagner, K. Nagel, and D. E. Wolf, "Realistic multi-lane traffic rules for cellular automata," Physica A: Statistical Mechanics and Its Applications, vol. 234, no. 3-4, pp. 687-698, 1997.

[20] J.-F. Tian, N. Jia, N. Zhu, B. Jia, and Z.-Z. Yuan, "Brake light cellular automaton model with advanced randomization for traffic breakdown," Transportation Research Part C: Emerging Technologies, vol. 44, pp. 282-298, 2014.

[21] J. Xun, B. Ning, K.-P. Li, and W.-B. Zhang, "The impact of end-to-end communication delay on railway traffic flow using cellular automata model," Transportation Research Part C: Emerging Technologies, vol. 35, pp. 127-140, 2013.

[22] C. Appert-Rolland and J. Du Boisberranger, "Macroscopic relaxation after on-ramps in real data and in cellular automata simulations," Transportation Research Part C: Emerging Technologies, vol. 34, pp. 162-175, 2013.

[23] Y.-J. Luo, B. Jia, X.-G. Li, C. Wang, and Z.-Y. Gao, "A realistic cellular automata model of bus route system based on open boundary," Transportation Research Part C: Emerging Technologies, vol. 25, pp. 202-213, 2012.

[24] Q. Meng and J. Weng, "An improved cellular automata model for heterogeneous work zone traffic," Transportation Research Part C: Emerging Technologies, vol. 19, no. 6, pp. 1263-1275, 2011.

[25] I. Spyropoulou, "Modelling a signal controlled traffic stream using cellular automata," Transportation Research Part C: Emerging Technologies, vol. 15, no. 3, pp. 175-190, 2007.

[26] C. F. Daganzo, "In traffic flow, cellular automata = kinematic waves," Transportation Research Part B: Methodological, vol. 40, no. 5, pp. 396-403, 2006.

[27] Greater Toronto Airport Authority, Taking Flight-The Airport Master Plan 2008-2030 [Master, thesis], Greater Toronto, 2008, https://www.torontopearson.com/en/gtaa/master-plan/\#. 


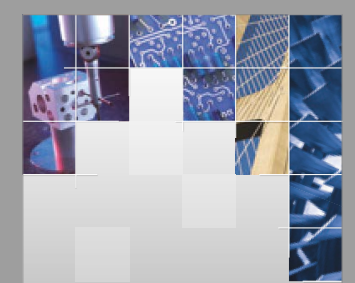

\section{Enfincering}
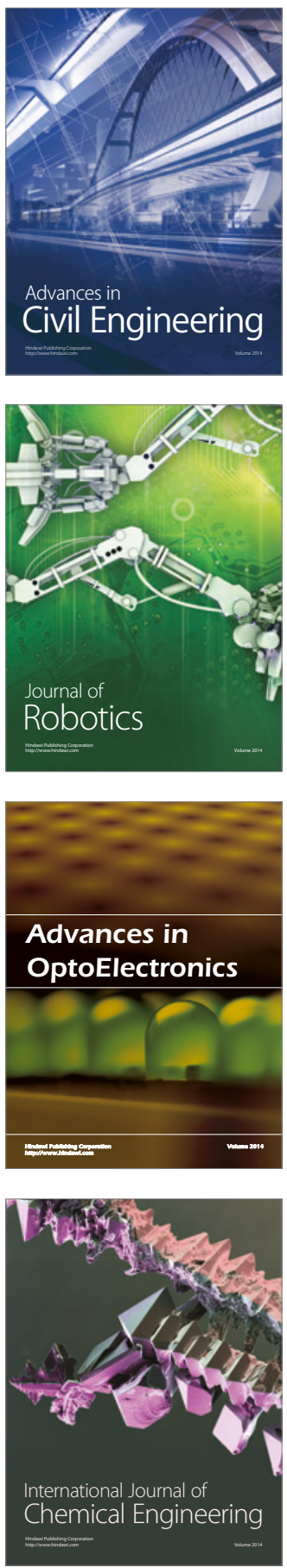

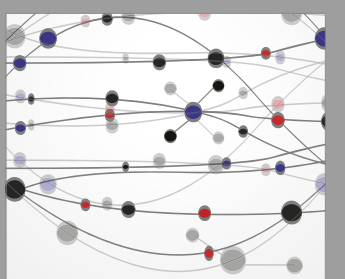

The Scientific World Journal

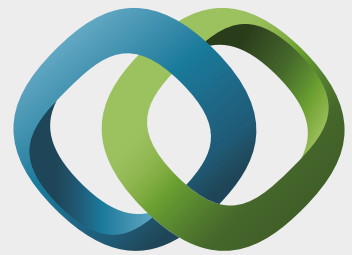

\section{Hindawi}

Submit your manuscripts at

https://www.hindawi.com
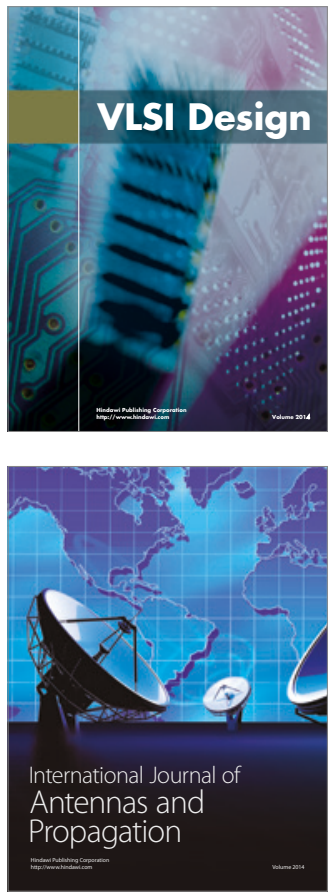

\section{Rotating}

Machinery
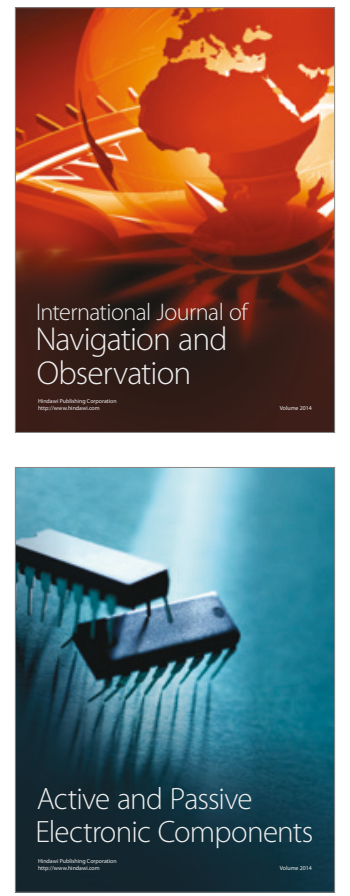
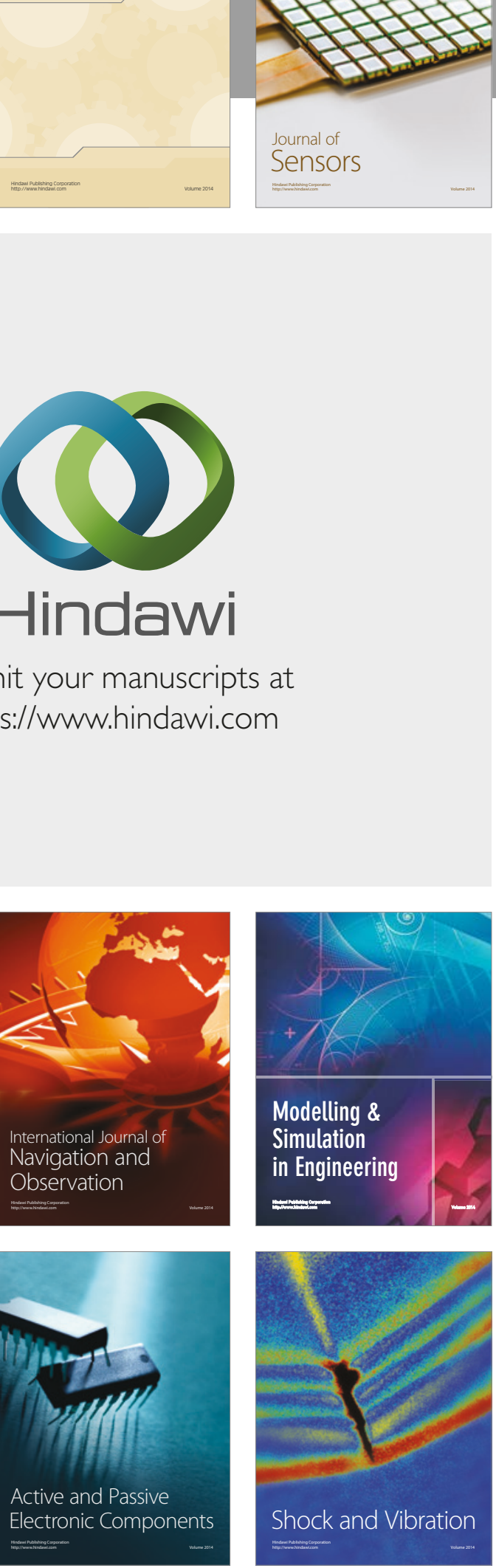
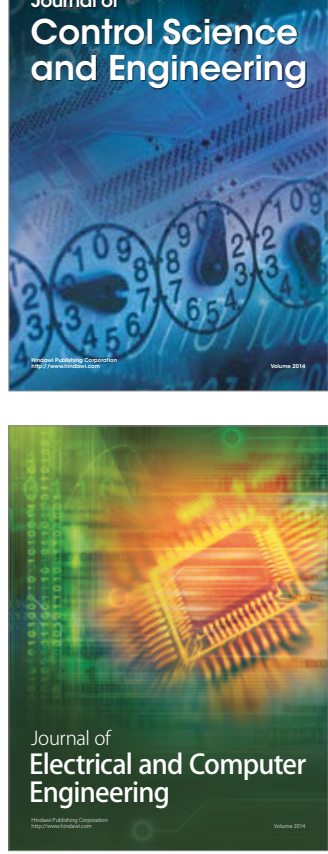

Distributed

Journal of

Control Science

and Engineering
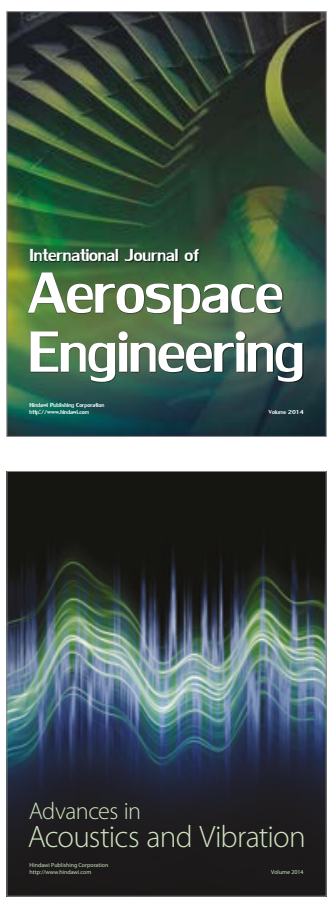

Sensor Networks 